\title{
Decision and Coordination in the Dual-Channel Supply Chain Considering the Risk-Averse and Customer Returns
}

\author{
Aifeng Zhang1, Jianbiao Ren ${ }^{2 *}$, Zhenzhong Guan1', Usman Farooq ${ }^{1}$ \\ ${ }^{1}$ School of Economics and Management, Southwest Jiaotong University, Chengdu, China \\ ${ }^{2}$ Antai College of Economics and Management, Shanghai Jiao Tong University, Shanghai, China \\ Email: ^jbren@sjtu.edu.cn
}

How to cite this paper: Zhang, A.F., Ren, J.B., Guan, Z.Z. and Farooq, U. (2021) Decision and Coordination in the Dual-Channel Supply Chain Considering the Risk-Averse and Customer Returns. Journal of Mathematical Finance, 11, 48-83. https://doi.org/10.4236/jmf.2021.111003

Received: November 4, 2020

Accepted: February 16, 2021

Published: February 19, 2021

Copyright $\odot 2021$ by author(s) and Scientific Research Publishing Inc. This work is licensed under the Creative Commons Attribution International License (CC BY 4.0).

http://creativecommons.org/licenses/by/4.0/ (c) (i) Open Access

\begin{abstract}
The biggest disadvantage of online shopping is that it is impossible to accurately assess the suitability of goods prior to purchase. Customers usually check "fit" at home, and thus one third of internet sales are returned. We study the pricing and ordering of a dual-channel supply chain which composed of risk-neutral manufacturers and risk-averse retailers serving customers who differ in how they purchase products in store or online. Customers may return misfit products either to stores for a full refund or online as per the retailer's return policy. At the beginning of the sale season, channels order from manufacturers and set prices to be identical across channels. According to the criterion of conditional value at risk $(\mathrm{CVaR})$, we express the problem as a Stackelberg game model and obtain the equilibrium solution under the conditions of decentralization and centralization. Further, we explore the impact of the retailer's risk indicator and consumer returns rate on the optimal retail price, the ordering quantities, the profits of dual channels, and the overall profits of the supply chain. We find that dual-channel supply should reduce the risk aversion level of retailers and consumer return rate. Finally, the improved risk-sharing contract is proposed to coordinate the dual-channel supply chain in the presence of customer returns and risk-averse, and it is proved that the contract can achieve Pareto improvement of supply chain members.
\end{abstract}

\section{Keywords}

Risk-Averse Retailers, Customer Returns, Dual-Channel Supply, Channel Coordination

\section{Introduction}

The biggest flaw of online shopping is that it can't accurately evaluate the fit of 
before products [1] [2]. Consumers can only receive products and try them out resulting in a large percentage of online sales being returned. In consequence, the return rate of fashion products purchased online is as high as $75 \%$. According to Vlachos and Dekker [3], Mostard and Teunter [4], Akcay et al. [5], the return rate of fashion products in physical channels is as high as 35\%. It's not surprise that the majority (66\%) (UPS 2014) customers evaluate the return policy before making a purchase, because the full refund policy is considered as an indicator of product quality [5] [6].

While retailers expand sales through the dual channels and full refund policies, it needs to face conflicts and uncertainties between channels, such as random market demand and manufacturers' uncertain output, and these uncertainties strongly affect the decision making of supply chain members that lead to the risk-avoiding characteristics of decision-makers [7]. Therefore, retailers may behave in a risk-averse way [8]. Interest in the risk aversion problem of members was proliferated in the early 1990s because it had attracted many scholars to study this interesting problem [9] [10] [11] [12] [13]. In this study, we also consider the dual-channel retailer's risk aversion into the decision framework in the customer return situation. Since traditional risk measurement methods cannot accurately measure the risk characteristics of decision-makers [7]. Therefore, the $\mathrm{CVaR}$ criterion is proposed to measure the degree of risk, which is considered to be superior to the risk value ( $\mathrm{VaR})$ because of its consistent measurement of risk and subadditivity [14]. CVaR has some attractive characteristics, such as consistency and convexity, which makes it more suitable for widely used in risk management measures than VaR [15]. In addition, $\mathrm{CVaR}$ has been extensively used to coordinate the dual-channel supply chain due to this it would be helpful to achieve a balance between expected profit and risk [7].

The contract mechanism is a common supply chain coordination method [7]. Supply chain coordination can be achieved through a certain contract, which can make the optimal decision of the decentralized supply chain equal to the optimal decision of the centralized supply chain [12]. Return policy is one of the most popular supply chain coordination strategies that had been studied extensively [6] [7] [12] [16] [17]. Related researches showed that traditional contracts, such as revenue sharing contract, buy-back contract, and wholesale price contract, cannot fully coordinate the dual-channel supply chain [7]. Then, how to coordinate the dual-channel supply chain becomes more challenging when considering risk preference and consumer return.

Research on the coordination of a dual channel supply chain with consumers' return focuses mainly on single channel companies. However, we analyze the decision making of the dual channel setting. This study considers the coordination of a dual-channel supply chain in which the risk-averse retailer adopts a dual-channel sales model and a full return strategy when the market demand is uncertain, assuming that the supplier is risk-neutral. Whereas customers purchase dual channel may or may not return misfit items depending on the firm's return policy. Keeping with the practices of most dual channel firms, the 
firm sets identical prices across its channels and allows free returns to its channel.

Our work is most closely related to Li et al. [10]. However, there are several significant differences between the two articles. The first is the background to the problem, Li et al. [18] assumed that the supplier with the direct channel is risk-neutral and his retailer is risk-averse, while we evaluate that the manufacturers sell their products at wholesale prices to risk averse dual channel retailers, which operate independently of each channel. The second is that we consider the retailer's risk preference and the return of consumers. In addition, we tempted to discuss the impact of channel return rate on the optimal price and order quantity of each channel and the overall benefits of the supply chain, and whether it is conducive to the overall development of the channel and the supply chain? Further, we explore the impact of the retailer's risk indicator and consumer returns rate on the optimal retail price, the ordering quantities, the profits of dual channels, and the overall profits of the supply chain. Similarly, from the improved risk-sharing contract in Li et al. [10], we design a new improved risk-sharing contract that coordinates the dual-channel supply chain and enables a win-win outcome for both the supplier and the retailer. Therefore, we do believe that the research in this study contributes to enrich the literature on risk-averse behavior and dual-channel supply coordination under consumer returns.

The rest of this paper is organized as follows. Section 2 is a related literature review. Section 3 presents a description of the problem. Section 4 introduces the decentralized optimal decision models when the retailer is risk-neutral and risk aversion and the concentrated optimal decision models when the retailer is risk aversion. Section 5 proposes an improved risk-sharing contract to coordinate a dual-channel supply chain. Section 6 provides numerical experiments, and Section 7 concludes. All proofs of propositions proposed in this paper are presented in Appendix A.

\section{Literature Review}

Many scholars have examined a refund policy in the study of consumer returns, and the return policy is exogenously identified as a full refund or Money Back Guarantee (MBG) [5] [8] [19] [20] [21]. Some researchers have compared the operating performance of a system without a refund policy and a system with a full refund policy or partial refund policy [8] [21] [22] [23] [24]. Most of the findings about consumer returns had focused on optimal decision and profit, such as Hsiao and Chen [25] found that the optimal refund policy may exceed the full price of the product. Additionally, Chen and Bell [26] and Su [23] had reported that the full refund policy is not the optimal strategy because it overwhelms the retailing system. Whereas, Chen and Zhang [22] founded the full refund strategy may be optimal when it has the competitors. Hu et al. [27] and Su [23] claimed that the optimal refund policy depends on the value of the refunded product. According to Li et al. [28], retailers should provide a lenient return policy with low quality 
and a low price or strict return policy with high quality and high price. Their choice depends on the customer's sensitivity to price, return policy, and quality.

With the in-depth study of customer return policy in operation management, scholars began to pay attention to know how customer returns affect the order, pricing, and supply chain coordination decision-making. For example, McWilliams [29] explored a competitive environment between high- and low-quality retailers where consumers are fully informed and risk-neutral, and retailers realize a salvage value for returned products and concluded that a full refund and return policy would benefit inferior retailers. Wang et al. [30] examined the impact of customer returns and bidirectional option contracts on a newspaper companies refund price and order decision. Xu et al. [31] investigated the effect of customer returns on customer behavior, retailer pricing, and ordering decisions. Batarfi et al. [32] revealed the influence of different return policies, including full, partial, and no refund policies on the order and pricing of the dual-channel supply chain, and found that generous return policies will result in higher selling prices and chain-wide profits. Lantz and Hjort [33] and Pei et al. [34] pointed out that the full return policies can enhance the consumers' purchase willingness and may increase market demand.

Several other investigations have considered customer returns in dual-channel retailing systems. Widodo et al. [35] [36] researched on both Nash and Stackelberg competitions between a retailer's physical and online channels considering customer returns. Further, they found that online customers were allowed to return products to the online store (a same-channel return) or the physical store (a cross-channel return). Radhi and Zhang [37] studied both same-channel and cross-channel returns encountered by a dual-channel retailer because it analyzes the effect that such returns have on optimal prices. Radhi and Zhang [38] analyzed the different same- and cross-channel resalable return policies and their impact on the optimal order quantities of the dual-channel retailer. However, this academic research has not addressed the risk aversion of the dual-channel retailer and not coordinated the supply chain with risk-averse retailers implement a full refund policy.

In recent years, cooperation and coordination in the supply chain have received great attention aroused. Contracts with various coordination mechanisms have been widely disseminated in supply chain coordination, for example, price discount contract [39], two-part tariff or a profit-sharing contract [40], two-way revenue sharing contract ([12] [41]), a two-part tariff contract ([42] [43]), revenue sharing contract ([44]). Studies on contracts that provide insights on how to coordinate a dual-channel supply chain are limited. Under the assumption of demand uncertainty and fixed prices in the retail channel and the direct channel, Boyaci [45] considered the uncertainty of demand and the price consistency between the retail channel and the manufacturer wholly-owned channel. They further founded wholesale price only, buyback, revenue-sharing, and Vendor Managed Inventory (VMI) contracts that cannot coordinate the dual-supply chain with inventory decisions. Xu et al. [12] proposed a contract (the two-way 
revenue sharing contract) in which they demonstrated by coordinating the dual-channel supply chain with risk-averse. Zhang et al. [46], Xu et al. [47], Zhu et al. [7] also studied the coordination of dual-channel supply chain under the stochastic customer demand. Cai [48] investigated the influence of channel structures and channel coordination on the supplier, the retailer, and the entire supply chain in the context of two single-channel and two dual-channel supply chains. Zhang et al. [49] designed a revenue sharing-contract to encourage the retailers to strive to recover waste products and proved the effectiveness of coordination mechanisms in alleviating retail price competition and improving the total profit of dual-channel closed-loop supply chain compared with the non-coordination model.

As seen from the related literature and to the best of authors' knowledge, no study has investigated the coordination of a dual-channel supply chain in which the retailer has risk-averse behavior under uncertainties of market demand and customers return unsuitable products. This study contributes to the literature in several aspects. First, we design a new improved risk-sharing contract that coordinates the dual-channel supply chain and enables a win-win outcome for both the supplier and the retailer. Second, we tempted to analyze the effects of customer return rate and retailer's risk-averse coefficient on the dual-channel supply chain. Third, this study contributes to the growing literature in the area by considering risk-averse behavior under uncertainties of market demand and customer returns.

\section{Description of the Problem}

This study describes the coordination of a dual-channel supply chain involving risk-neutral manufacturers and risk-averse retailers under consumer returns, in which the manufacturer is the leader of the supply chain who sells product to retailers at wholesale price $w$. We assume that the manufacturer's unit production cost is $c$, which is generally simplified to 0 . The retailer will sell products to consumers through the online channel and the traditional retailer channel at the same prices $p_{o}$ and $p_{n}$, respectively, the surplus value of the products at the end of the sales season is zero. At the same time, the dual channels are independent of each other, and there is only one ordering opportunity before the sales season.

The parameters are defined as follows:

\footnotetext{
$r$ or $o$ Represent the traditional retail channel and the online channel, respectively.

$D$ Refers the primary market demand (i.e., the potential demand if the goods are free of charge).

$D_{i} \quad$ Presents the demand from the traditional retail channel or the online channel ( $i=r$ or $o$ ), Describes the retailer's order quantity to the supplier at the beginning of the sales period

$q_{i} \quad(i=r$ or $o)$.

$a_{i} \quad$ Represents the self-price sensitivity of channels $(i=r$ or $o)$.

$\sigma_{i} \quad$ Refers the cross-channel price sensitivity of channels $(i=r$ or $o$ ).

$\theta$ Presents the degree of customer acceptance in the traditional retailer channel, correspondingly, 1- $\theta$ represents the degree of customer acceptance in the online retailer channel.
} 
According to Huang and Swaminathan [50], Chen et al. [40], the corresponding demand function for the retailer channel $r$ and the online channel $o$ are as follows:

$$
\begin{gathered}
D_{r}=\theta \bar{D}-a_{r} p_{r}+\sigma_{r} p_{o} \\
D_{o}=(1-\theta) \bar{D}-a_{o} p_{o}+\sigma_{o} p_{r}
\end{gathered}
$$

We assume $a_{i}>\sigma_{i}$, where signifies that the effect of the cross-channel price is lower that of the self-channel price [51]. The actual demand is often stochastic; we assume that the uncertain demand $\bar{D}$ is a random variable, as follows: $\bar{D}=D+x$. Here, $D$ is the initial potential demand and $x$ is a random number that reflects the degree of demand uncertainty. Its probability density function and cumulative distribution function are $f(x)$ and $F(x)$, respectively. For the convenience of calculation, we assume that $x$ follows a uniform distribution on $[-U, U], 0 \leq U \leq D$ and $D \geq U$.

Referring to Kevin [52] and Li et al. ([10] [18]), the price is assumed to be identical across channels. Cavallo [53] finds that $70 \%$ of retailers have identical pricing across channels, even more so (92\%) for clothing products, and that differences, if any, are negligible. Thus, we adopt the same assumption that the price for two channels is consistent in the following, namely $p_{r}=p_{o}=p$. It can also be explained that in the competition with online retailers, traditional retailers are leaders who decide the retail price of products, and online channels follow the same price. Consequently, the demand functions under this pricing strategy can be written as:

$$
\begin{gathered}
D_{r}=\theta \bar{D}-r_{1} p \\
D_{o}=(1-\theta) \bar{D}-r_{2} p
\end{gathered}
$$

where $r_{1}=a_{r}-\sigma_{r}, r_{2}=a_{o}-\sigma_{o}, r_{2}>r_{1}$. They are the self-channel price sensitivity on the two channels. Without losing generality, we assume $p \geq w$ to avoid a trivial case.

Moreover, the number of customer returns has a strong positive linear relationship with the quantity sold which is proved by the results of Anderson et al. [54] and Hess and Mayhew [55]. Vlachos and Dekker [3] have also assumed customer returns were a fixed proportion of quantity sold. Thus, we adopt the same assumption on the customer returns for the dual-channel in the following, that returns function is $R_{i}\left(D_{i}, q_{i}\right)=\beta_{i} \min \left\{D_{i}, q_{i}\right\} \quad\left(i=r\right.$ or $o$ ), where $0<\beta_{i}<1$ is the return rate in dual channel, $\beta_{i}=0$ corresponds to the case of no product returns. We also assume that the customer receives a full refund for a returned product from the retailers and the return rate of the online channel is higher than the traditional channel, that is $\beta_{o}>\beta_{r}$. The framework of the dual-channel supply chain is shown in Figure 1.

Further, risk measurement methods include the mean-variance method, the $V a R$ method, and the $C V a R$ method. Wu et al. [9] showed that $C V a R$ had advantages than the mean-variance method and the Value-at-Risk in both theory and application. So, we adopt the $C V a R$ method as the measure of a retailer's 


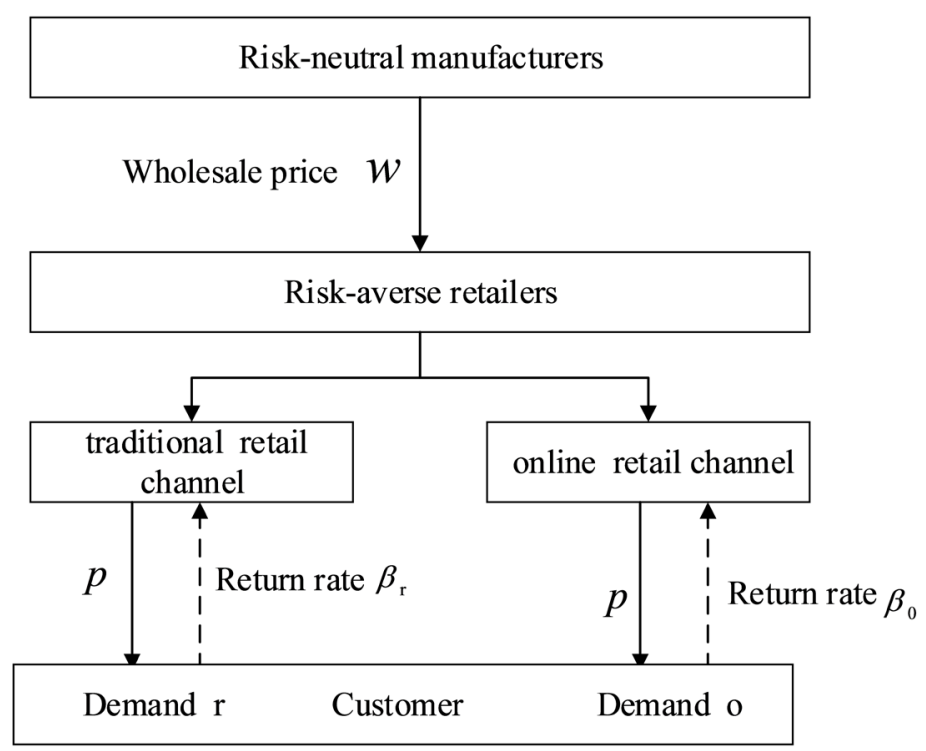

Figure 1. Framework of dual channel supply chain.

risk. To clearly demonstrate the retailer's risk aversion affects the channel members' strategies, we consider two cases: 1) the retailers are risk-neutral and 2) the retailers are risk-averse under the $C V a R$ criterion.

\section{The Decentralized Optimal Decision Model}

In the following, we suppose that the three agents play a Stackelberg game in a dual-channel supply chain, i.e., first, the supplier acts as the leader, decides the wholesale price $w$. After observing the supplier's decisions, the traditional retailer acts as decider for optimal order quantity and optimal pricing. Afterwards, the online retailer observes the traditional retailer's optimal pricing and decides the optimal order quantity.

\subsection{The Equilibrium Solutions under the Risk-Neutral}

Let's consider the $\pi_{r}^{d}, \pi_{o}^{d}$ and $\pi_{m}^{d}$ to be the profit function of the traditional retailer, the online retailer and the supplier under the decentralized model. So, they are as following:

$$
\begin{gathered}
\pi_{r}^{d}=p \min \left\{q_{r}, D_{r}\right\}-w q_{r}-p R_{i} \\
\pi_{o}^{d}=p \min \left\{q_{o}, D_{o}\right\}-w q_{o}-p R_{o} \\
\pi_{m}^{d}=w\left(q_{r}+q_{o}\right)
\end{gathered}
$$

According to $\min \left\{q_{i}, D_{i}\right\}=q_{i}-\left(q_{i}-D_{i}\right)^{+}, \quad\left(q_{i}-D_{i}\right)^{+}=\max \left\{q_{i}-D_{i}, 0\right\}$, $i=r$ or $o$, we can obtain:

$$
\begin{aligned}
& \pi_{r}^{d}=\left(\left(1-\beta_{r}\right) p-w\right) q_{r}-\left(1-\beta_{r}\right) p\left(q_{r}-D_{r}\right)^{+} \\
& \pi_{o}^{d}=\left(\left(1-\beta_{o}\right) p-w\right) q_{o}-\left(1-\beta_{o}\right) p\left(q_{o}-D_{o}\right)^{+}
\end{aligned}
$$

Then, we can obtain the following proposition 1 . 
Proposition 1: When the condition $D>3 U$ is satisfied, there exists a unique equilibrium solution $\left(q_{r}^{d^{*}}, p^{d^{*}}, q_{o}^{d^{*}}, w^{d^{*}}\right)$ under the Stackelberg model.

1) The risk-neutral traditional retailer's optimal order quantity and optimal pricing are noted $q_{r}^{d^{*}}$ and $p^{d^{*}}$ satisfies the following equation

$$
\begin{gathered}
q_{r}^{d^{*}}=(U+D) \theta-r_{1} p^{d^{*}}-\frac{2 U \theta w^{d^{*}}}{\left(1-\beta_{r}\right) p^{d^{*}}} \\
2 r_{1} p^{d^{* 3}}\left(1-\beta_{r}\right)^{2}-r_{1} w^{d^{*}} p^{d^{* 2}}\left(1-\beta_{r}\right)-D \theta p^{d^{* 2}}\left(1-\beta_{r}\right)^{2}+\theta U w^{d^{* 2}}=0
\end{gathered}
$$

2) The risk-neutral online retailer's optimal order quantity is

$$
q_{o}^{d^{*}}=(U+D)(1-\theta)-r_{2} p^{d^{*}}-\frac{2 U(1-\theta) w^{d^{*}}}{\left(1-\beta_{o}\right) p^{d^{*}}}
$$

3) The supplier's optimal wholesale price satisfies the following equation:

$$
U+D-r_{1} p^{d^{*}}-r_{2} p^{d^{*}}-\frac{4 U \theta w^{d^{*}}}{\left(1-\beta_{r}\right) p^{d^{*}}}-\frac{4 U(1-\theta) w^{d^{*}}}{\left(1-\beta_{o}\right) p^{d^{*}}}=0
$$

The proof is given in Appendix 1.

Next, we use the $C V a R$ measures to explore the impact of retailer's risk-averse on decision-making.

\subsection{The Equilibrium Solutions under the Conditional Value-at-Risk Criterion}

Reference to Li et al. [10] and Rockafellar and Uryasev [14], the CVAR of a traditional retailer can be expressed as:

$$
\begin{aligned}
\operatorname{CVaR}^{\eta}\left(\pi_{r}^{c}\right) & =E\left[\pi_{r}^{c} \leq v^{\eta}\left(\pi_{r}^{d}\right)\right] \\
& =\max _{v \in \mathbb{R}}\left\{v+\frac{1}{\eta} E\left[\min \left(\pi_{r}^{c}-v, 0\right)\right]\right\}
\end{aligned}
$$

Similarly, $\eta$ is the retailer's risk indicator and $v$ is the target profit lever. This formula can measure the average profit below the level of $\eta$-quantile level, ignores the profit contribution beyond the prescribed quantile.

That is:

$$
\begin{aligned}
& \operatorname{CVaR}^{\eta}\left(\pi_{r}^{c}\right) \\
& =\max _{v \in \mathbb{R}}\left\{v+\frac{1}{\eta} E\left[\min \left(\left(\left(1-\beta_{r}\right) p-w\right) q_{r}-\left(1-\beta_{r}\right) p\left(q_{r}-D_{r}\right)^{+}-v, 0\right)\right]\right\}
\end{aligned}
$$

According to Li et al. [10], we simplify formula (14) to obtain the following:

$$
\operatorname{CVaR}^{\eta}\left(\pi_{r}^{c}\right)=\left\{\begin{aligned}
\left(1-\beta_{r} p\right) q_{r}-w q_{r}-\frac{\left(1-\beta_{r}\right) p \theta}{\eta} \int_{-U}^{\frac{q_{r}+r_{1} p}{\theta}-D} F(x) \mathrm{d} x & \\
& \text { if } q_{r} \leq \theta D-R_{1} P+\theta F^{-1}(\eta) \\
\left(1-\beta_{r}\right) p \theta F^{-1}(\eta)+\left(1-\beta_{r}\right) p \theta D-r_{1} p^{2}\left(1-\beta_{r}\right)-w q_{r}-\frac{\left(1-\beta_{r}\right) p \theta}{\eta} \int_{-U}^{F^{-1}(\eta)} F(x) \mathrm{d} x & \\
& \text { if } q_{r}>\theta D-R_{1} P+\theta F^{-1}(\eta)
\end{aligned}\right.
$$


This simplification and analysis process is given in Appendix 2.

If $q_{r}>\theta D-r_{1} p+\theta F^{-1}(\eta)$,

$$
\begin{gathered}
\operatorname{CVaR}^{\eta}\left(\pi_{r}^{c}\right)=\left(1-\beta_{r}\right) p \theta F^{-1}(\eta)+\left(1-\beta_{r}\right) p \theta D-r_{1} p^{2}\left(1-\beta_{r}\right) \\
-w q_{r}-\frac{\left(1-\beta_{r}\right) p \theta}{\eta} \int_{-U}^{F^{-1}(\eta)} F(x) \mathrm{d} x \\
\text { Because } \frac{\partial C \operatorname{VaR}^{\eta}\left(\pi_{r}^{c}\right)}{\partial q_{r}}=-w<0 \text {, so can be obtained } q_{r}^{*}=\theta D-r_{1} p+\theta F^{-1}(\eta) .
\end{gathered}
$$

Obviously, this is also the boundary of the first case, so we only study the first case.

That is, when $q_{r}>\theta D-R_{1} P+\theta F^{-1}(\eta)$,

$$
\operatorname{CVaR}^{\eta}\left(\pi_{r}^{c}\right)=\left(\left(1-\beta_{r}\right) p-w\right) q_{r}-\frac{\left(1-\beta_{r}\right) p \theta}{\eta} \int_{-U}^{\frac{q_{r}+r_{1} p}{\theta}-D} F(x) \mathrm{d} x
$$

Similarly, the profit function of online retailers is

$$
\operatorname{CVaR}^{\eta}\left(\pi_{o}^{c}\right)=\left(\left(1-\beta_{o}\right) p-w\right) q_{o}-\frac{\left(1-\beta_{o}\right) p(1-\theta)}{\eta} \int_{-U}^{\frac{q_{r}+r_{1} p}{1-\theta}-D} F(x) \mathrm{d} x
$$

According to the above analysis, the decision-making problem of each member of the supply chain becomes:

$$
\begin{gathered}
\pi_{m}^{c}=w\left(q_{r}+q_{o}\right) \\
\max _{q_{r}, p} C \operatorname{VaR}^{\eta}\left(\pi_{r}^{c}\right)=\left(\left(1-\beta_{r}\right) p-w\right) q_{r}-\frac{\left(1-\beta_{r}\right) p \theta}{\eta} \int_{-U}^{\frac{q_{r}+r_{1} p}{\theta}-D} F(x) \mathrm{d} x \\
\max _{q_{o}} \operatorname{CVaR}^{\eta}\left(\pi_{o}^{c}\right)=\left(\left(1-\beta_{o}\right) p-w\right) q_{o}-\frac{\left(1-\beta_{o}\right) p(1-\theta)}{\eta} \int_{-U}^{\frac{q_{o}+r_{2} p}{1-\theta}-D} F(x) \mathrm{d} x
\end{gathered}
$$

Proposition 2: Under the Condition Value-at-Risk criterion, if the demand uncertainty $x$ obeys the uniform distribution of $[-U, U]$, there is a unique equilibrium solution $\left(q_{r}^{c^{*}}, p^{c^{*}}, q_{o}^{c^{*}}, w^{c^{*}}\right.$ ) under the Stackelberg model.

1) The traditional retailer's optimal order quantity and optimal pricing are noted $q_{r}^{c^{*}}$ and $p^{c^{*}}$ satisfies the following equation:

$$
\begin{aligned}
q_{r}^{c^{*}} & =(D-U) \theta-r_{1} p^{c^{*}}+\frac{2 U \theta \eta\left(\left(1-\beta_{r}\right) p^{c^{*}}-w^{c^{*}}\right)}{\left(1-\beta_{r}\right) p^{c^{*}}} \\
& 2 r_{1} p^{c^{*} 3}\left(1-\beta_{r}\right)^{2}-r_{1} w^{c^{*}} p^{c^{*} 2} 2\left(1-\beta_{r}\right) \\
& -(D-(1-\eta) U) \theta p^{c^{*} 2}\left(1-\beta_{r}\right)^{2}+\theta U \eta w^{c^{*} 2}=0
\end{aligned}
$$

2) The risk-neutral online retailer's optimal order quantity is:

$$
q_{o}^{c^{*}}=(D-U)(1-\theta)-r_{2} p^{c^{*}}+\frac{2 u \eta(1-\theta)\left(\left(1-\beta_{o}\right) p^{c^{*}}-w^{c^{*}}\right)}{\left(1-\beta_{o}\right) p^{c^{*}}}
$$

3) The supplier's optimal wholesale price satisfies the following equation:

$$
U+D-r_{1} p^{c^{*}}-r_{2} p^{c^{*}}+2 U \eta-\frac{4 U \eta \theta w^{c^{*}}}{\left(1-\beta_{r}\right) p^{c^{*}}}-\frac{4 U \eta(1-\theta) w^{c^{*}}}{\left(1-\beta_{o}\right) p^{d^{*}}}=0
$$


The proof is given in Appendix 3.

At this time, the optimal profit of the physical channel and the online channel are as follows:

$$
\begin{aligned}
\pi_{r}^{c^{*}}= & \left(1-\beta_{r}\right) p^{c^{*}}\left((D-U) \theta-r_{1} p^{c^{*}}+U \eta \theta\right)-w(D-U) \theta \\
& +r_{1} p^{c^{*}}-2 U \eta \theta w+\frac{U \eta \theta w^{2}}{\left(1-\beta_{r}\right) p} \\
\pi_{o}^{c^{*}}= & \left(1-\beta_{o}\right)(1-\theta)(D-U+U \eta) p^{c^{*}}-\left(1-\beta_{o}\right) r_{2} p^{c^{*} 2} \\
& -(D-U)(1-\theta) w+r_{2} p^{c^{*}} w-2 U \eta(1-\theta) w+\frac{U \eta(1-\theta) w^{2}}{\left(1-\beta_{o}\right) p^{c^{*}}}
\end{aligned}
$$

Accordingly, the total optimal profit of the supply chain is

$$
\Pi_{s c}^{c^{*}}=w^{c^{*}}\left(q_{r}^{c^{*}}+q_{o}^{c^{*}}\right)
$$

Proposition 3: Under the CVaR criterion, the following properties are satisfied.

1) $p^{c^{*}}$ increase as the rate return of physical channel $\beta_{r}$ increase,

2) $q_{r}^{c^{*}}$ decrease as $\beta_{r}$ increase,

3) $\pi_{r}^{c^{*}}$ decrease as $\beta_{r}$ increase,

4) $q_{o}^{c^{*}}$ is negatively correlated with $\beta_{o}$,

5) $\pi_{o}^{c^{*}}$ is negatively correlated to $\beta_{o}$.

The proof is given in Appendix 4.

Proposition 3 explains that the rate return of physical channel affects the optimal price and demand of physical channels. Furthermore, the rate return of physical channel $\beta_{r}$ tends to 0 , the optimal profit of physical channels will increase. The effect of the return rate of the online channel on the online channel is similar to the above. In general, channels increase their retail price to make up for the losses caused by customer returns, resulting in a reduction in channel demand and a corresponding decrease in channel profits.

Proposition 4: Under the CVaR criterion, when the condition $\frac{r_{1}}{r_{2}}>\frac{\theta}{2(1-\theta)}$ and $\frac{1-\beta_{o}}{r_{1}} s\left(q_{o}^{*}\right)>\left(1-\beta_{o}\right) p^{c^{*}}-w$ are satisfied, the following properties are satisfied.

With the increase of the retailer's risk-averse level $\eta$ in [0,1], the optimal pricing $p^{c^{*}}$ and the optimal order quantity $q_{r}^{c^{*}}, q_{o}^{c^{*}}$ and the optimal profit of dual channel $\pi_{r}^{c^{*}}, \pi_{o}^{c^{*}}$ and the total optimal profit of the supply chain increase monotonically.

Where, $s\left(q_{o}^{*}\right)=(D-U+U \eta)(1-\theta)-r_{2} p^{c^{*}}-\frac{U \eta(-\theta) w^{2}}{\left(1-\beta_{r}\right)^{2} p^{c^{* 2}}}$, this is also the expected sales volume of online channels.

The proof is given in Appendix 5.

Proposition 4 indicates that the optimal retail pricing, order quantity and profits depend on its risk-averse. With the channels risk-averse level $\eta$ in- 
creases, the retailer has an optimistic attitude towards the market, the traditional physical retailer will raise the retail price and dual channel will increase the order quantity accordingly. At the same time, the optimal profits of each channel are also increasing. Suppliers also get benefit from retailers' positive attitude, which increases their operating profit. Then, the retailer risk-averse $\eta$ can increase the total profit of the supply chain. The degree of risk aversion of retailers affects the degree of damage to the interests of all members of the supply chain.

\subsection{The Centralized Optimal Decision Model}

In the centralized supply chain, the supply chain decides the optimal retail price and dual channel's order quantity at the same time. Under centralized decisions, the profit function of the supply chain is as follow:

$$
\begin{aligned}
\max _{p, q_{r}, q_{o}} \Pi_{s c}= & \pi_{m}+C \operatorname{VaR}^{\eta}\left(\pi_{r}\right)+\operatorname{CVaR}^{\eta}\left(\pi_{o}\right) \\
= & \left(1-\beta_{r}\right) p q_{r}-\frac{\left(1-\beta_{r}\right) p \theta}{\eta} \int_{-U}^{\frac{q_{r}+r_{1} p}{\theta}-D} F(x) \mathrm{d} x \\
& +\left(1-\beta_{o}\right) p q_{o}-\frac{\left(1-\beta_{o}\right) p(1-\theta)}{\eta} \int_{-U}^{\frac{q_{o}+r_{2} p}{1-\theta}-D} F(x) \mathrm{d} x
\end{aligned}
$$

with the formula (22), we have the following result:

Proposition 5: There exists a unique equilibrium solution of optimal retail prices and dual channels optimal order quantity $\left(p^{*}, q_{r}^{*}, q_{o}^{*}\right)$ under centralized decision mode.

$$
\begin{gathered}
p^{*}=\frac{(D-U+U \eta)\left(\left(1-\beta_{r}\right) \theta+\left(1-\beta_{o}\right)(1-\theta)\right)}{2 r_{1}\left(1-\beta_{r}\right)+2 r_{2}\left(1-\beta_{o}\right)} \\
q_{r}^{*}=(D-U) \theta-r_{1} p^{*}+2 U \eta \theta \\
q_{o}^{*}=(D-U)(1-\theta)-r_{2} p^{*}+2 U \eta(1-\theta)
\end{gathered}
$$

The proof is given in Appendix 6.

From the above analysis, the optimal profit function of the whole supply chain to be rewritten as follows:

$$
\Pi_{s c}^{*}=\left(1-\beta_{r}\right) p^{*} s\left(q_{r}^{*}\right)+\left(1-\beta_{o}\right) p^{*} s\left(q_{o}^{*}\right)
$$

where, $s\left(q_{r}^{*}\right)=(D-U+U \eta) \theta-r_{1} p^{*}, \quad s\left(q_{o}^{*}\right)=(D-U+U \eta)(1-\theta)-r_{2} p^{*}$.

Proposition 6: In the centralized situation, the following properties are satisfied.

When the coordination $\frac{r_{1}}{r_{2}}>\max \left\{\frac{\theta}{4(1-\theta)}-\frac{3\left(1-\beta_{o}\right)}{4\left(1-\beta_{r}\right)}, \frac{1-\beta_{o}}{2\left(1-\beta_{r}\right)}\left(\frac{\theta}{1-\theta}-1\right)\right\}$ is stratified, the optimal retail price $p^{*}$ and order quantity $q_{r}^{*}$, $q_{o}^{*}$ of dual channel and the optimal profit of the supply chain $\Pi_{s c}^{*}$ increase monotonically as the retailer's risk-averse level $\eta$ increase in $[0,1]$.

The proof is given in Appendix 7.

Proposition 6 shows that the optimal strategy of the dual-channel supply chain is closely related to the risk preference behavior of the retailer's dual 
channel. When the retailer's risk-averse indicator $\eta$ tends to 1 , it means that the retailer has a positive and optimistic attitude towards the market, thereby increasing the number of orders and the retail price, and the total profit of the supply chain is also improved. Therefore, manufacturers should mitigate the retailers' risk-averse behavior to improve their own and total supply chain operating performance and increase operating profits.

Proposition 7: In the centralized situation, the following properties are satisfied.

1) the optimal retail price $p^{*}$ and the optimal profit of the supply chain $\Pi_{s c}^{*}$ decrease monotonically as the physical channels customer returns rate $\beta_{r}$ increase in $(0,1)$, but the optimal order quantity $q_{r}^{c^{*}}$ increases monotonically as it increases.

2) the optimal retail price $p^{*}$ increase monotonically as the online channel $s$ customer returns rate $\beta_{o}$ increases in $(0,1)$, but the optimal order quantity $q_{r}^{c^{*}}$ and the optimal profit of the supply chain $\Pi_{s c}^{*}$ decrease monotonically as it increases.

The proof is given in Appendix 8.

Proposition 7 indicates that the optimal retail price $p^{*}$ will be significantly affected by the consumer returns rate of dual channels. When the physical channel's return rate increases, it will force the retailer to reduce the retail prices to attract more consumers and to make up for the losses caused by returns. But when the online channel's return rate increases, the physical channel as the decision-maker of the retail price will increase the optimal retail price. Therefore, with the customer returns rate of physical channels increases, its optimal order quantity gradually increases. However, with the customer return rate of online channels increases, its optimal order quantity gradually decreases. From the perspective of operation, the consumer returns behavior must damage the retailer's profit. Proposition 7 also verifies the correctness of this conclusion.

Corollary 1: The decentralized optimal pricing is not equal to the optimal pricing under the centralized decision-making, that is $p^{c^{*}} \neq p^{*}$, the profit of the supply chain in the decentralized situation will deviate from the optimal profit in the centralized situation.

The proof is given in Appendix 9.

Corollary 1 expatiates that the overall optimal profit of the supply chain under decentralized decision-making is still lower than that under centralized decision-making. As we know, decentralized decision-making reduces the overall efficiency of the supply chain. Next, we design a new contract to improve the overall performance of the supply chain and increase the profits of its members.

\section{An Improved Risk-Sharing Contract}

Referring to Li et al. (2016) we propose an improved risk-sharing contract to coordinate the supply chain and to achieve the improved operation performance of the supply chain under centralized decision-making and achieve Pareto improvement of each member. This contract is composed of wholesale price con- 
tract, revenue-sharing contract and risk-return contract, and use $(w, \lambda, b)$ expresses it, where $w$ is the wholesale price of the supplier, $\lambda$ is the retailer's revenue-sharing ratio and $b$ is the ratio of supplier's repurchase to retailer's expected surplus inventory. Thus the profit functions of the supplier and two channels of retailer are, respectively:

$$
\begin{aligned}
& \pi_{m}^{s}\left(\lambda_{1}, \lambda_{2}, b_{1}, b_{2}\right)= w\left(q_{r}+q_{o}\right)+\left(1-\lambda_{1}\right)\left(1-\beta_{r}\right) p\left[q_{r}-\frac{\theta}{\eta} \int_{-U}^{\frac{q_{r}+r_{1} p}{\theta}-D} F(x) \mathrm{d} x\right] \\
&+\left(1-\lambda_{2}\right)\left(1-\beta_{o}\right) p\left[q_{o}-\frac{1-\theta}{\eta} \int_{-U}^{\frac{q_{o}+r_{2} p}{1-\theta}-D} F(x) \mathrm{d} x\right] \\
&-\frac{b_{1} \theta}{\eta} \int_{-U}^{\frac{q_{r}+r_{1} p}{\theta}-D} F(x) \mathrm{d} x-\frac{b_{2}(1-\theta)}{\eta} \int_{-U}^{\frac{q_{o}+r_{2} p}{1-\theta}-D} F(x) \mathrm{d} x \\
& \operatorname{CVaR}^{\eta}\left(\pi_{r}^{s}\left(\lambda_{1}, b_{1}\right)\right)= \lambda_{1}\left(1-\beta_{r}\right) p\left(q_{r}-\frac{\theta}{\eta} \int_{-U}^{\frac{q_{r}+r_{1} p}{\theta}-D} F(x) \mathrm{d} x\right) \\
&+\frac{b_{1} \theta}{\eta} \int_{-U}^{\frac{q_{r}+r_{1} p}{\theta}-D} F(x) \mathrm{d} x-w q_{r} \\
& \operatorname{CVaR}^{\eta}\left(\pi_{o}^{s}\left(\lambda_{2}, b_{2}\right)\right)= \lambda_{2}\left(1-\beta_{o}\right) p\left(q_{o}-\frac{1-\theta}{\eta} \int_{-U}^{\frac{q_{o}+r_{2} p}{1-\theta}-D} F(x) \mathrm{d} x\right) \\
&+\frac{b_{2}(1-\theta)}{\eta} \int_{-U}^{\frac{q_{o}+r_{2} p}{1-\theta}-D} F(x) \mathrm{d} x-w q_{o}
\end{aligned}
$$

Proposition 8: When the condition $D>\frac{r_{1} b_{1}}{\lambda_{1}\left(1+\beta_{r}\right) \theta}+\frac{\left(2+\eta^{2}\right) U}{\eta}$ is satisfied, there exists a unique equilibrium solution of the retail price and dual channels optimal order quantity and optimal wholesale price $\left(p^{s^{*}}, q_{r}^{s^{*}}, q_{o}^{s^{*}}, w^{s^{*}}\right)$ when the supply chain adopts this contract.

1) The optimal retail price $p^{s^{*}}$ satisfies the formula

$$
(D-U) \theta-2 r_{1} p^{s^{*}}-\frac{\theta \eta U A^{2}}{B^{2}}+\frac{A}{B} 2 U \eta \theta+\frac{r_{1} w^{s^{*}}}{\lambda_{1}\left(1-\beta_{r}\right)}=0
$$

2) The traditional retailer's optimal order quantity satisfies the following equation

$$
q_{r}^{s^{*}}=\frac{\left(\lambda_{1}\left(1-\beta_{r}\right) p^{s^{*}}-w^{s^{*}}\right) 2 U \eta \theta}{\lambda_{1}\left(1-\beta_{r}\right) p^{s^{*}}-b_{1}}+(D-U) \theta-r_{1} p^{s^{*}}
$$

3) The online retailer's optimal order quantity satisfies the following equation

$$
q_{o}^{s^{*}}=\frac{\left(\lambda_{2}\left(1-\beta_{o}\right) p^{s^{*}}-w^{s^{*}}\right) 2 U \eta(1-\theta)}{\lambda_{2}\left(1-\beta_{o}\right) p^{s^{*}}-b_{2}}+(D-U)(1-\theta)-r_{2} p^{s^{*}}
$$

4) The supplier's optimal wholesale price satisfies the following equation:

$$
\begin{aligned}
& D-U-r_{1} p^{s^{*}}-r_{2} p^{s^{*}}+\frac{2 U \eta \theta \lambda_{1}\left(1-\beta_{r}\right) p^{s^{*}}}{\lambda_{1}\left(1-\beta_{r}\right) p^{s^{*}}-b_{1}}-\frac{4 U \eta \theta w^{s^{*}}}{\left(1-\beta_{r}\right) p^{s^{*}} b_{1}} \\
& -\frac{4 U \eta(1-\theta) w^{s^{*}}}{\left(1-\beta_{o}\right) p^{s^{*}}-b_{2}}+\frac{2 U \eta(1-\theta) \lambda_{2}\left(1-\beta_{o}\right) p^{s^{*}}}{\lambda_{2}\left(1-\beta_{o}\right) p^{s^{*}}-b_{2}}=0
\end{aligned}
$$


where, $A=\lambda_{1}\left(1-\beta_{r}\right) p^{s^{*}}-w^{s^{*}}, B=\lambda_{1}\left(1-\beta_{r}\right) p^{s^{*}}-b_{1}$.

The proof is given in Appendix 10.

Proposition 9: Under an improved risk-sharing contract, if $w=b_{1}=b_{2}=b$ and $\theta<\bar{\theta}$, then $p^{*}=p^{s^{*}}, q_{r}^{*}=q_{r}^{s^{*}}, q_{o}^{*}=q_{o}^{s^{*}}$. At this point, the total profit of the supply chain is equal to that in the centralized situation.

Where,

$$
\begin{aligned}
b= & \frac{\left(1-\beta_{r}\right)(D-U+U \eta)}{r_{1}\left(2 r_{1}\left(1-\beta_{r}\right)+2 r_{2}\left(1-\beta_{o}\right)\right)}\left(r_{1}\left(1-\beta_{o}\right)(1-\theta)\left(1+\lambda_{1}\left(1-\beta_{r}\right)\right)\right. \\
& \left.-\left(r_{1}\left(1-\beta_{r}\right)+2 r_{2}\left(1-\beta_{o}\right)-r_{1} \lambda_{1}\left(1-\beta_{r}\right)^{2}\right) \theta\right), \\
\bar{\theta}= & \frac{r_{1}\left(1-\beta_{o}\right)\left(1+\lambda_{1}\left(1-\beta_{r}\right)\right)}{r_{1}\left(1-\beta_{r}+1-\beta_{o}\right)+r_{1} \lambda_{1}\left(1-\beta_{r}\right)\left(1-\beta_{o}\right)+2 r_{2}\left(1-\beta_{o}\right)-r_{1} \lambda_{1}\left(1-\beta_{r}\right)^{2}} .
\end{aligned}
$$

According to $q_{r}^{*}=q_{r}^{s^{*}}$ and $q_{o}^{*}=q_{o}^{s^{*}}$ we can get $w=b_{1}=b_{2}=b$. Then bring $p^{*}$ into the equation

$(D-U) \theta-\left(1+\lambda_{1}\left(1-\beta_{r}\right) r_{1} p^{*}\right)-+2 U \theta \eta \frac{A}{B}-U \eta \theta \frac{A}{B}+\frac{r_{1} w}{1-\beta_{r}}=0$ can get $b$.

Proposition 9 shows that the improved risk-sharing contract achieves the coordination of the two-channel supply chain. When the condition $\theta<\bar{\theta}$ is satisfied, for any $\lambda_{1} \in(0,1)$, the $b$ is always nonnegative. This phenomenon illustrates that no matter how much profit the retailer shares with the supplier, the manufacturer must bear the retailer's loss caused by the risk aversion and it is worth noting that manufacturers bear the same proportion of double channel losses. This seems contrary to common sense, but the careful study is consistent with reality because we assume that the risk aversion of dual channels is the same, the resulting losses are directly related to this. So there is a phenomenon that suppliers share the same proportion of revenue to the dual channels.

This condition $\theta<\bar{\theta}$ indicates that only when the market share of traditional physical channels is low, the traditional physical channels would like to accept this contract. Otherwise, when $\bar{\theta}<\theta<1$, there is $w=b_{1}=b_{2}<0$, this contract is unable to achieve the coordination of the dual-channel supply chain because the supplier will not accept this contract. But in the early stage of supplier development, if he wants retailers to help him to develop the market, this contract may be accepted by him and achieve the dual-channel supply chain coordination.

\section{Numerical Examples}

In this section, we do use numerical simulation to verify the validity and reliability of the above model. We first examine the effect of the improved risk-sharing contract by comparing the equilibrium solutions of centralized supply chains and the decentralized supply chains with the improved risk-sharing contract, we can get the following Corollary 2.

Corollary 2: Under the improved risk-sharing contract, there exists a group 
of $\left\{\lambda_{1}^{*}, \lambda_{2}^{*}, b^{*}\right\}$ to make members of the supply chain gain a win-win outcome. In other words, there are regions that satisfy the following conditions

$$
\begin{aligned}
\operatorname{CVaR}^{\eta}\left(\pi_{r}^{s^{*}}\left(\lambda_{1}^{*}, b_{1}^{*}\right)\right)> & \operatorname{CVaR}^{\eta}\left(\pi_{r}^{c^{*}}\right), \operatorname{CVaR}^{\eta}\left(\pi_{o}^{s^{*}}\left(\lambda_{2}^{*}, b_{2}^{*}\right)\right)>\operatorname{CVaR}^{\eta}\left(\pi_{o}^{c^{*}}\right) \\
& \text { and } \pi_{m}^{s}\left(\lambda_{1}^{*}, \lambda_{2}^{*}, b_{1}^{*}, b_{2}^{*}\right)>\pi_{m}^{c^{*}} .
\end{aligned}
$$

where $\operatorname{CVaR}^{\eta}\left(\pi_{r}^{s^{*}}\left(\lambda_{1}^{*}, b_{1}^{*}\right)\right), \quad \operatorname{CVaR}^{\eta}\left(\pi_{o}^{s^{*}}\left(\lambda_{2}^{*}, b_{2}^{*}\right)\right), \pi_{m}^{s}\left(\lambda_{1}^{*}, \lambda_{2}^{*}, b_{1}^{*}, b_{2}^{*}\right)$ shows the optimal profit of dual channels retailer and the supplier under the improved risk-sharing contract. Similarly, $\operatorname{CVaR}^{\eta}\left(\pi_{r}^{c^{*}}\right), \mathrm{CVaR}^{\eta}\left(\pi_{o}^{c^{*}}\right)$ and $\pi_{m}^{c^{*}}$ represents the optimal profit of dual channels retailer and the supplier under the decentralized situation (Figure 2). From Figure 2, we can see that there is a Pareto zone with the share proportions $\lambda_{1}$ and $\lambda_{2}$. This contract achieves the perfect coordination of the supply chain and can make a win-win outcome for everyone. Because more than one set of $\left\{\lambda_{1}^{*}, \lambda_{2}^{*}, b_{1}^{*}, b_{2}^{*}\right\}$ achieving perfect coordination, the bargaining power among members determines the profit distribution among them. It is equivalent to determining the specific coordination parameter values of $\left\{\lambda_{1}^{*}, \lambda_{2}^{*}, b_{1}^{*}, b_{2}^{*}\right\}$. According to Li et al. (2016), we assume that other parameter values are $U=25, D=100, r_{1}=0.8, r_{2}=1, \theta=0.3, \eta=0.8, \quad \beta_{r}=0.2$, $\beta_{o}=0.3$.

Next, we will analyze the impact of the physical channel customer's returns rate $\beta_{r}$ on the optimal profit of the supply chain $\Pi_{s c}^{c^{*}}$. Let $U=100, D=600$, $r_{1}=0.8, r_{2}=1, \beta_{o}=0.35, w=15$. It considers three cases as follows: 1) $\theta=0.6, \eta=0.8$ 2) $\theta=0.7, \eta=0.8$ 3) $\theta=0.6, \eta=0.9$, the specific results are shown in Figure 3.

From Figure 3, it can see that $\Pi_{s c}^{c^{*}}$ decrease as the physical channel customer returns rate $\beta_{r}$ increase under three cases. This means that the customer returns

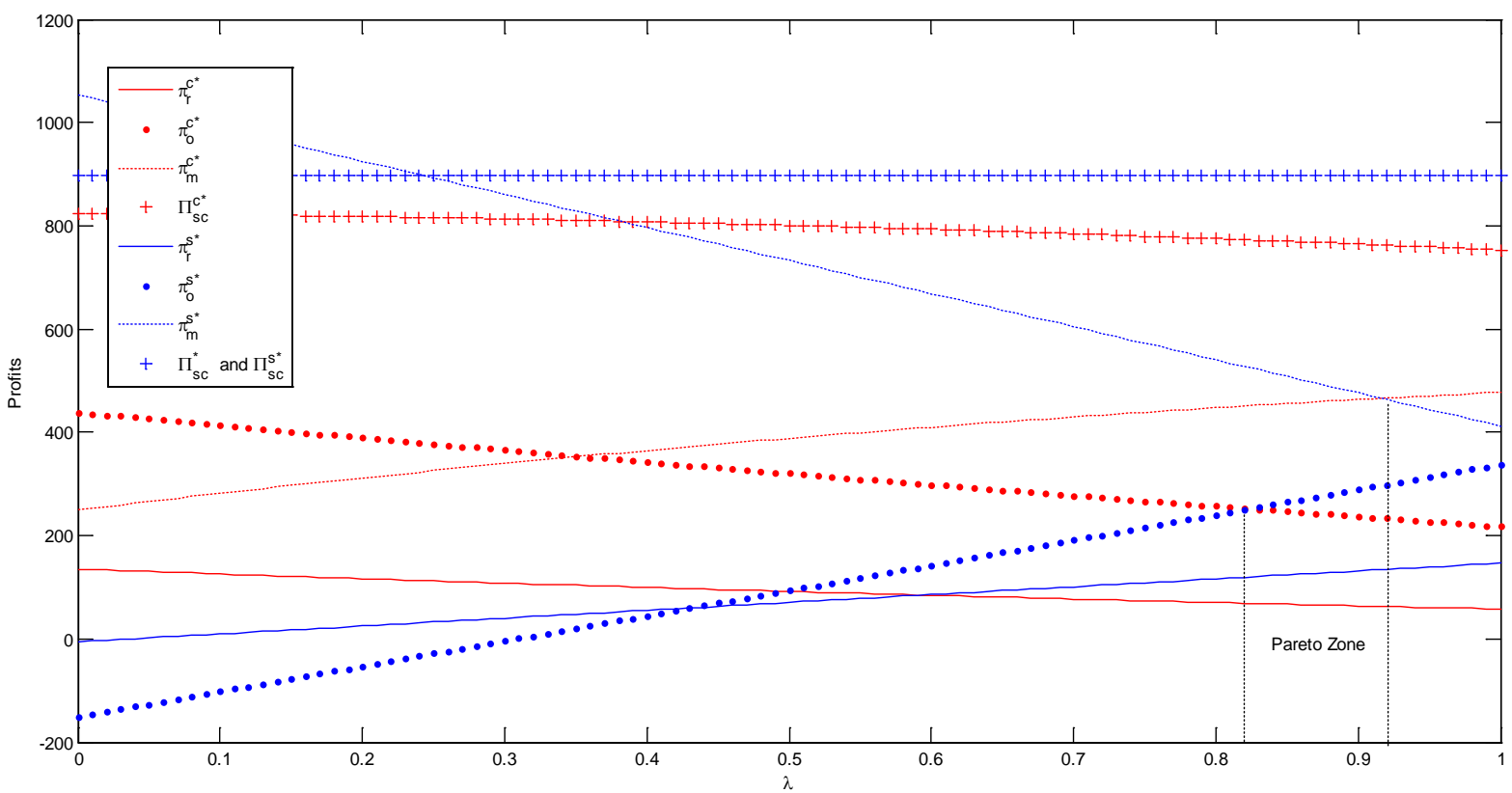

Figure 2. The agents' profits change with respect to the share proportions $\lambda_{1}$ and $\lambda_{2}$. 


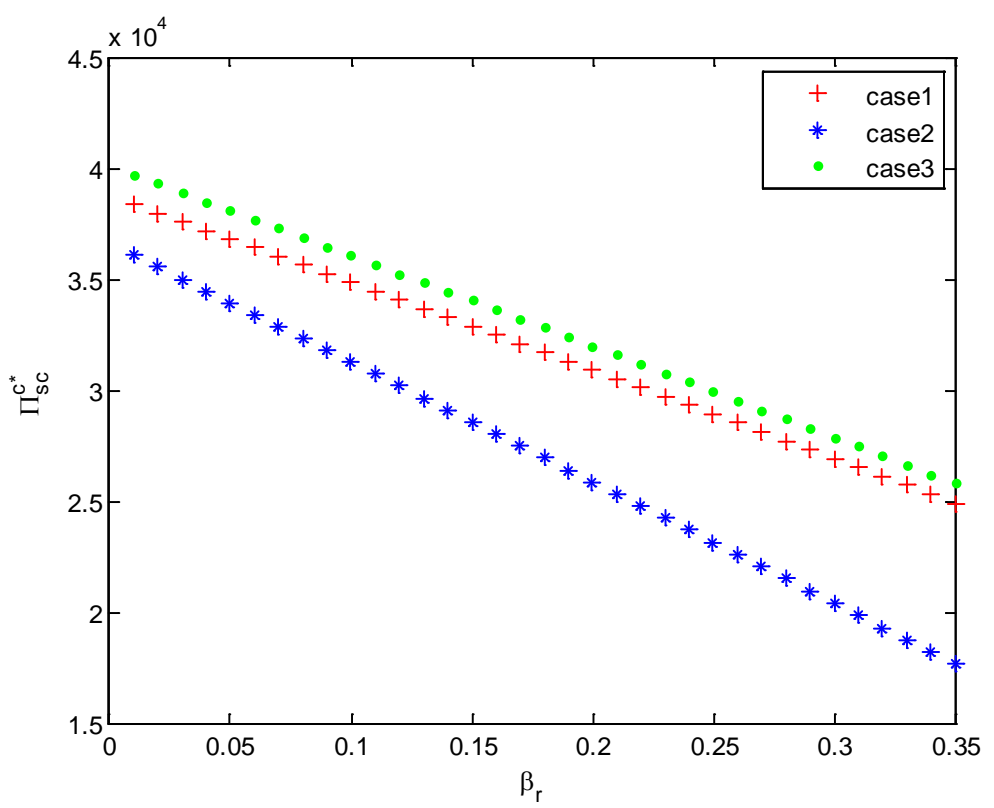

Figure 3. the impacts of the physical channel customer's return rate $\beta_{r}$ on $\Pi_{s c}^{c^{*}}$.

damages the interests of the supply chain. Therefore, retailers should actively look for the reasons for consumers' return and draft the corresponding solutions to reduce the return rate and to increase the operating efficiency of themselves and the supply chain and increase the operating profit.

Similarly, we do discuss the impact of the online channel customer returns rate $\beta_{o}$ on the optimal profit of the supply chain below. $\Pi_{s c}^{c^{*}}$. Let $U=100$, $D=600, r_{1}=0.8, r_{2}=1, \beta_{r}=0.2$. It considers three cases as follows: 1$)$ $\theta=0.6, \theta=0.6$ 2) $\theta=0.55, \eta=0.8$ 3) $\theta=0.6, \eta=0.9$. The results are shown in Figure 4.

From Figure 4, it can see that $\Pi_{s c}^{c^{*}}$ decrease as the physical channel customers' return rate $\beta_{o}$ increase under three cases. The return behavior of consumers is unfavorable to each member of the supply chain. The retailers should carefully analyze the main reasons for consumer returns in various channels and strive to reduce the return rate to achieve the purpose of increasing the competitiveness of the supply chain and improving the operational efficiency of the supply chain.

Then, we do analyze the impact of the retailer's risk-averse level $\eta$ on the equilibriums solutions $p^{c^{*}}, q_{r}^{c^{*}}, \pi_{r}^{c^{*}}, q_{o}^{c^{*}}, \pi_{o}^{c^{*}}, \Pi_{s c}^{c^{*}}$. Let $D=100, r_{2}=1$, $\beta_{r}=0.1, \beta_{o}=0.2, w=13$. It considers three cases as follows: 1) $U=25$, $\theta=0.5, r_{1}=0.8$ 2) $U=25, \theta=0.5, r_{1}=1$ 3) $U=15, \theta=0.53, r_{1}=0.8$. The specific results are shown in Figures 5-7.

The influence of risk aversion level on the optimal profit of online channels is also closely related to other parameters. From Figure 5, as the retailer's risk aversion is reduced ( $\eta$ increase), the optimal retail price of the dual channel will increase accordingly. By comparing case 1 and case 2 , we can see that as the price sensitivity of physical channel increases, the optimal retail price will decrease. 


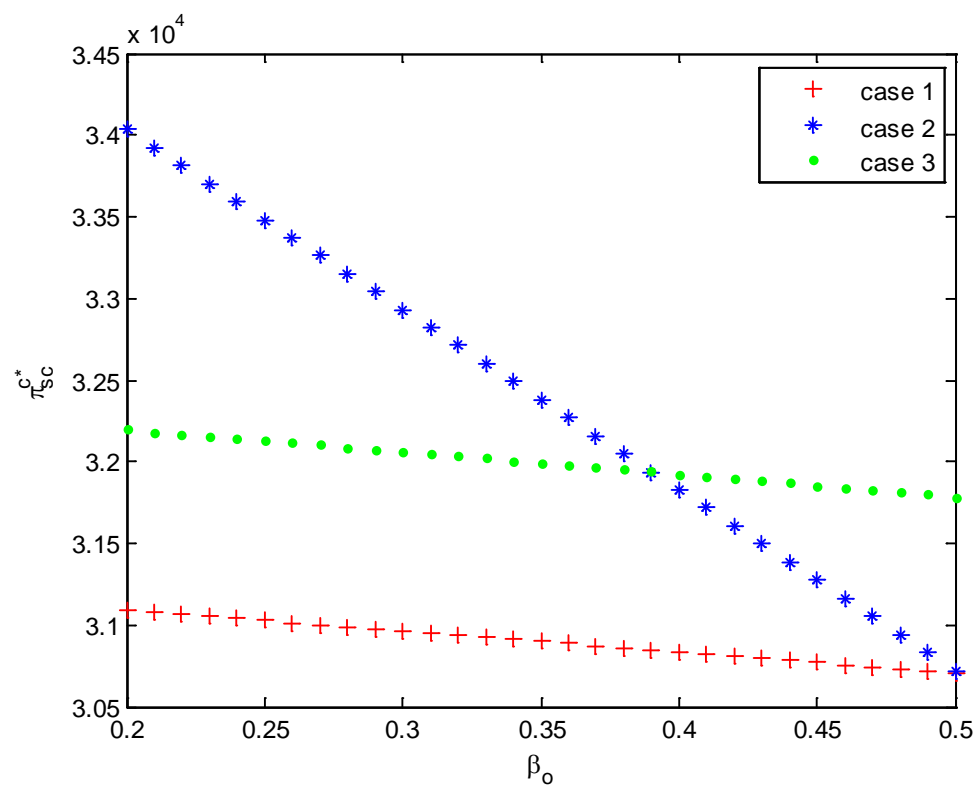

Figure 4. the impacts of the physical channel customer's return rate $\beta_{o}$ on $\Pi_{s c}^{c^{*}}$.

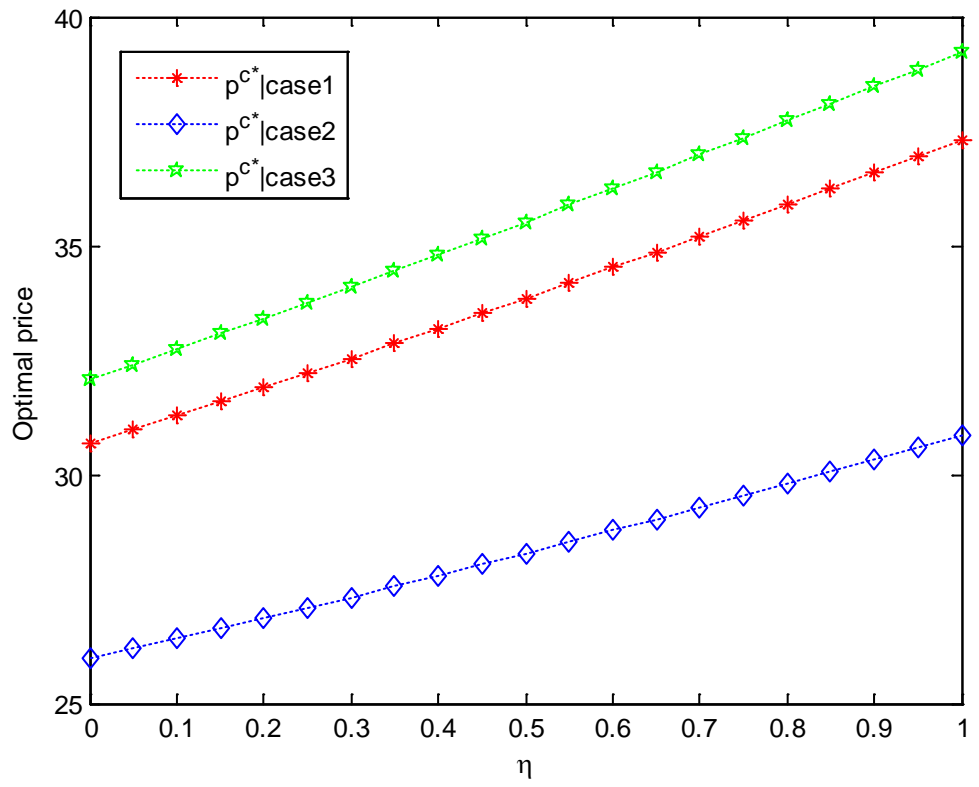

Figure 5. The impact of the retailer's risk-averse level on the optimal pricing $p^{c^{*}}$.

It explains that when the price sensitivity of consumers to the physical channel increases, retailers will reduce the retail price to attract more consumers.

From Figure 6, as the retailer's risk aversion is reduced ( $\eta$ increase), the optimal order quantity of two channels will increase accordingly. The retailer's risk-averse parameter $\eta$ increase means that it has enough confidence in the market's prospects, so it will increase its order volume, thereby avoiding the loss of customers caused by shortages.

From Figure 7, as the retailer's risk aversion is reduced ( $\eta$ increase), the optimal profits of the two channels and supply chain will increase accordingly. 

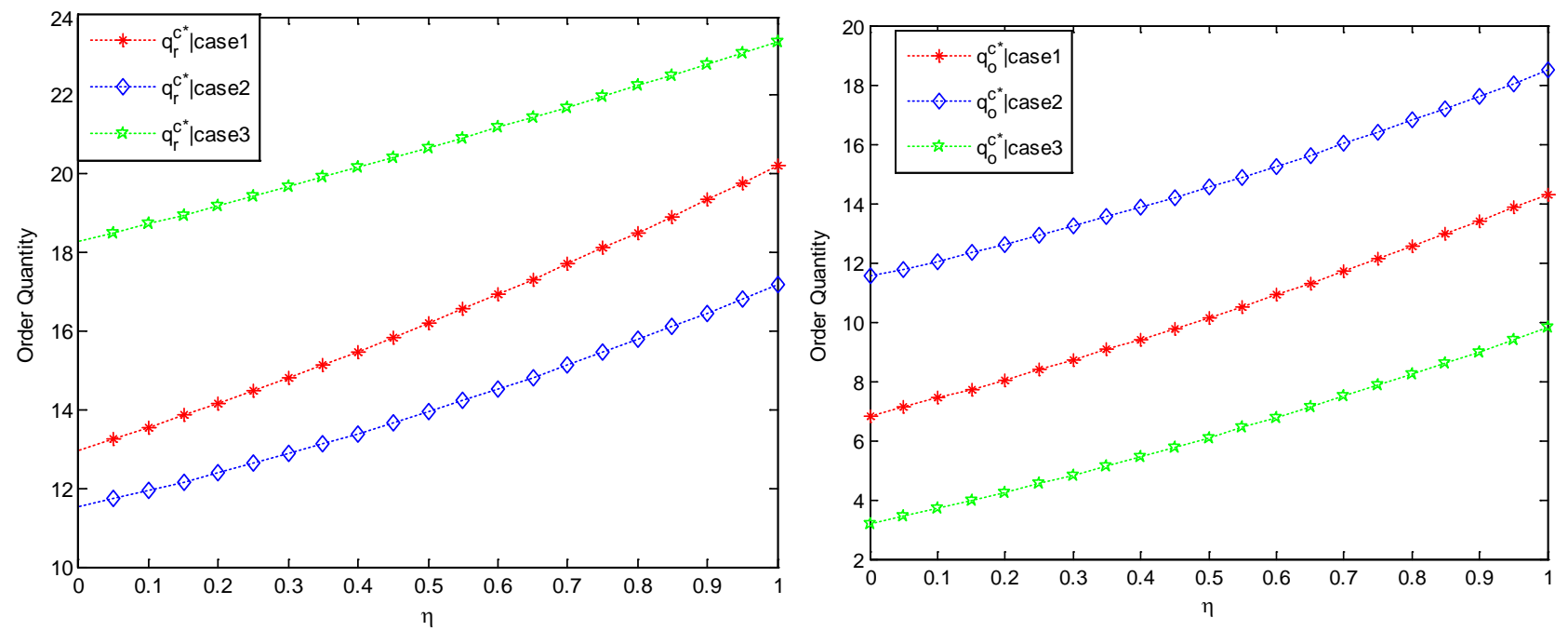

Figure 6. The impact of the retailer's risk-averse level on the optimal order quantity $q_{r}^{c^{*}}$ and $q_{0}^{c^{*}}$.
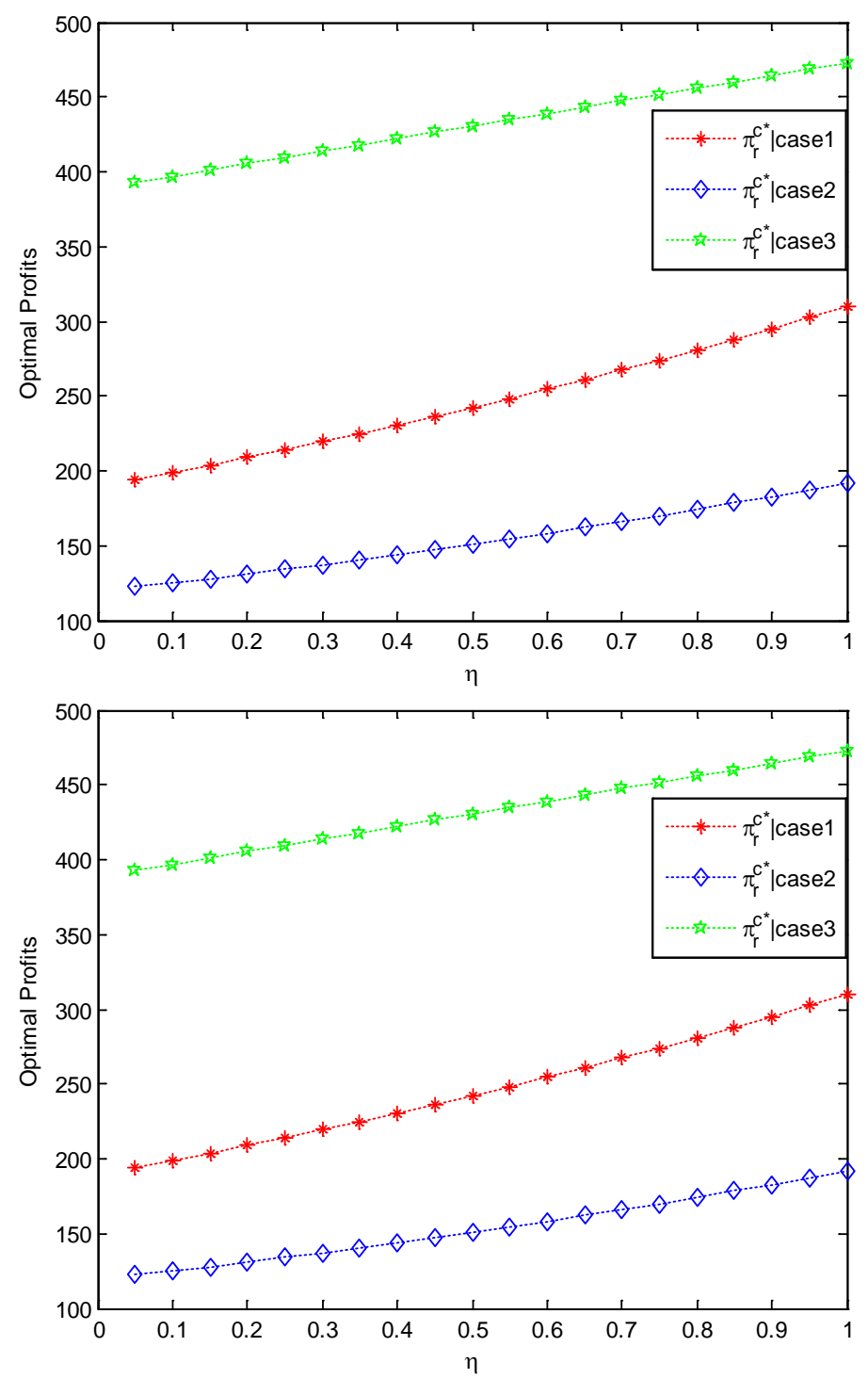


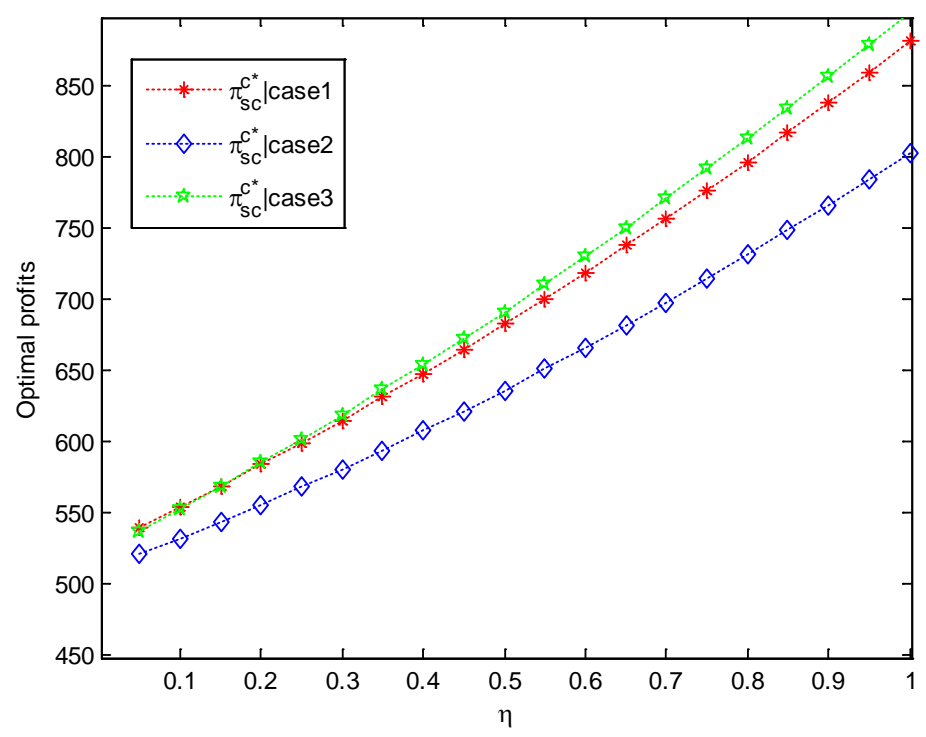

Figure 7. The impact of the retailer's risk-averse level on $\pi_{r}^{c^{*}}$ and $\pi_{o}^{c^{*}}$ and $\Pi_{s c}^{c^{*}}$.

With the risk-averse indicator $\eta$ increasing, the physical channel, the online channel, and supply chain will get benefit from it. Therefore, manufacturers should take a series of measures to mitigate the risk aversion of retailers to improve the overall operational efficiency of the supply chain and increase the operating profits.

\section{Conclusion}

In this study, we investigated a distribution channel that includes a risk-neutral manufacturer and a risk-averse retailer who implements the dual-channel sales model. We have concluded that they play a Stackelberg game and both face uncertain market demand. Through analysis, we solved the equilibrium solution and proposed a contract that can coordinate the supply chain. Propositions and numerical analysis indicated our conclusions and further explored the impact of some parameters on the equilibrium solutions. We showed that when the retailer's channels become more risk-averse, the optimal retail price will decrease and dual channels will decrease the optimal order quantity. The risk behavior of the channels always damages the interests of all members and the supply chain. Further, the return rate of physical channels reduces the optimal retail prices, while the return rate of online channels contributes to increasing the optimal retail prices. Then, we consciously proposed a proper risk-sharing contract to coordinate the dual-channel supply chain. Moreover, we proved that it is impossible to coordinate the supply chain with only wholesale price contracts. Finally, an improved risk-sharing contract is proposed that enables the coordination of the supply chain and Pareto improvement of members.

\section{Conflicts of Interest}

The authors declare no conflicts of interest regarding the publication of this paper. 


\section{References}

[1] Cilley, J. (2016) Apparel \& Footwear Retail Survey Report. Technical Report, Body Labs, Inc., New York.

[2] Nageswaran, L., Cho, S.-H. and Scheller-Wolf, A. (2020) Consumer Return Policies in Omnichannel Operations. Management Science, 66, 5485-6064.

[3] Vlachos, D. and Dekker, R. (2003) Return Handling Options and Order Quantities for Single Period Products. European Journal of Operational Research, 151, 38-52. https://doi.org/10.1016/S0377-2217(02)00596-9

[4] Mostard, J. and Teunter, R. (2006) The Newsboy Problem with Resalable Returns: A Single Period Model and Case Study. European Journal of Operational Research, 169, 81-96. https://doi.org/10.1016/j.ejor.2004.04.048

[5] Akcay, Y., Boyaci, T. and Zhang, D. (2013) Selling with Money-Back Guarantees: The Impact on Prices, Quantities, and Retail Profitability. Production and Operations Management, 22, 777-791. https://doi.org/10.1111/j.1937-5956.2012.01394.x

[6] Chen, J. and Grewal, R. (2013) Competing in a Supply Chain via Full-Refund and No-Refund Customer Returns Policies. International Journal of Production Economics, 146, 246-258. https://doi.org/10.1016/j.ijpe.2013.07.005

[7] Zhu, B., Wen, B., Ji, S. and Qiu, R. (2020) Coordinating a Dual-Channel Supply Chain with Conditional Value-at-Risk under Uncertainties of Yield and Demand. Computers \& Industrial Engineering, 139, Article ID: 106181. https://doi.org/10.1016/j.cie.2019.106181

[8] Choi, T.M., Liu, N., Ren, S. and Hui, C.L. (2013) No Refund or Full Refund: When Should a Fashion Brand Offer Full Refund Consumer Return Service for Mass Customization Products. Mathematical Problems in Engineering, 2013, Article ID: 561846. https://doi.org/10.1155/2013/561846

[9] Wu, J., Wang, S., Chao, X., Ng, C.T. and Cheng, T.C.E. (2010) Impact of Risk Aversion on Optimal Decisions in Supply Contracts. International Journal of Production Economics, 128, 569-576. https://doi.org/10.1016/j.ijpe.2010.04.049

[10] Li, B., Hou, P.W., Chen, P. and Li, Q.H. (2016) Pricing Strategy and Coordination in a Dual Channel Supply Chain with a Risk-Averse Retailer. International Journal of Production Economics, 178, 154-168. https://doi.org/10.1016/j.ijpe.2016.05.010

[11] Liu, N., Choi, T., Yuen, C.M. and Ng F. (2012) Optimal Pricing, Modularity, and Return Policy under Mass Customization. IEEE Transactions on Systems, Man, and Cybernetics-Part A: Systems and Humans, 42, 604-614. https://doi.org/10.1109/TSMCA.2011.2170063

[12] Xu, G., Dan, B., Zhang, X. and Liu, C. (2014) Coordinating a Dual-Channel Supply Chain with Risk-Averse under a Two-Way Revenue Sharing Contract. International Journal of Production Economics, 147, 171-179. https://doi.org/10.1016/j.ijpe.2013.09.012

[13] Li, B. and Jiang, Y. (2019) Impacts of Returns Policy under Supplier Encroachment with Risk-Averse Retailer. Journal of Retailing and Consumer Services, 47, 104-115. https://doi.org/10.1016/j.jretconser.2018.11.011

[14] Rockafellar, R.T. and Uryasev, S. (2000) Optimization of Conditional Value-at-Risk. Journal of Risk, 2, 21-42. https://doi.org/10.21314/JOR.2000.038

[15] Xu, X., Meng, Z. and Shen, R. (2013) A Tri-Level Programming Model Based on Conditional Value-at-Risk for Three-Stage Supply Chain Management. Computers \& Industrial Engineering, 66, 470-475. https://doi.org/10.1016/j.cie.2013.07.012

[16] Pasternack, B.A. (1985) Optimal Pricing and Returns Policies for Perishable Com- 
modities. Marketing Science, 4, 166-176. https://doi.org/10.1287/mksc.4.2.166

[17] Xiao, T.J., Shi, K.R. and Yang, D.Q. (2010) Coordination of a Supply Chain with Consumer Return under Demand Uncertainty. International Journal of Production Economics, 124, 171-180. https://doi.org/10.1016/j.ijpe.2009.10.021

[18] Li, B., Chen, P., Li, Q. and Wang, W. (2014) Dual-Channel Supply Chain Pricing Decisions with a Risk-Averse Retailer. International Journal of Production Research, 52, 7132-7147. https://doi.org/10.1080/00207543.2014.939235

[19] Reimann, M. (2016) Accurate Response with Refurbished Consumer Returns. Decision Sciences, 47, 31-59. https://doi.org/10.1111/deci.12150

[20] Chang, S.Y. and Yeh, T.Y. (2013) A Two-Echelon Supply Chain of a Returnable Product with Fuzzy Demand. Applied Mathematical Modelling, 37, 4305-4315. https://doi.org/10.1016/j.apm.2012.09.043

[21] Chen, J. and Bell, P. (2013) The Impact of Customer Returns on Supply Chain Decisions under Various Channel Interactions. Annals of Operations Research, 206, 59-74. https://doi.org/10.1007/s10479-013-1326-3

[22] Chen, J. and Zhang, H. (2011) The Impact of Customer Returns on Competing Chains. International Journal of Management Science and Engineering Management, 6, 58-70. https://doi.org/10.1080/17509653.2011.10671147

[23] Su, X. (2009) Customer Returns Policies and Supply Chain Performance. Manufacturing \& Service Operations Management, 11, 595-612.

https://doi.org/10.1287/msom.1080.0240

[24] Yalabik, B., Petruzzi, N. and Chhajed, D. (2005) An Integrated Product Returns Model with Logistics and Marketing Coordination. European Journal of Operational Research, 161, 162-182. https://doi.org/10.1016/j.ejor.2003.07.006

[25] Hsiao, L. and Chen, Y.J. (2012) Returns Policy and Quality Risk in e-Business. Production and Operations Management, 21, 489-503. https://doi.org/10.1111/j.1937-5956.2011.01285.x

[26] Chen, J. and Bell, P. (2009) The Impact of Customer Returns on Pricing and Order Decisions. European Journal of Operational Research, 195, 280-295.

https://doi.org/10.1016/j.ejor.2008.01.030

[27] Hu, W., Li, Y. and Govindan, K. (2014) The Impact of Consumer Returns Policies on Consignment Contracts with Inventory Control. European Journal of Operational Research, 233, 398-407. https://doi.org/10.1016/j.ejor.2013.03.015

[28] Li, Y., Xu, L. and Li, D. (2013) Examining Relationships between the Return Policy, Product Quality, and Pricing Strategy in Online Direct Selling. International Journal of Production Economics, 144, 451-460. https://doi.org/10.1016/j.ijpe.2013.03.013

[29] McWilliams, B. (2012) Money-Back Guarantees: Helping the Low-Quality Retailer. Management Science, 58, 1521-1524. https://doi.org/10.1287/mnsc.1110.1497

[30] Wang, C., Chen, J. and Chen, X. (2019) The Impact of Customer Returns and Bidirectional Option Contract on Refund Price and Order Decisions. European Journal of Operational Research, 274, 267-279. https://doi.org/10.1016/j.ejor.2018.09.023

[31] Xu, L., Li, Y., Govindan, K. and Xu, X. (2015) Consumer Returns Policies with Endogenous Deadline and Supply Chain Coordination. European Journal of Operational Research, 242, 88-99. https://doi.org/10.1016/j.ejor.2014.09.049

[32] Batarfi, R., Jaber, M.Y. and Aljazzar, S.M. (2017) A Profit Maximization for a Reverse Logistics Dual-Channel Supply Chain with a Return Policy. Computers \& Industrial Engineering, 106, 58-82. https://doi.org/10.1016/j.cie.2017.01.024

[33] Lantz, B. and Hjort, K. (2013) Real E-Customer Behavioral Responses to Free Deli- 
very and Free Returns. Electronic Commerce Research, 13, 183-198. https://doi.org/10.1007/s10660-013-9125-0

[34] Pei, Z., Paswan, A. and Yan, R. (2014) E-Tailer's Return Policy, Consumer's Perception of Return Policy Fairness and Purchase Intention. Journal of Retailing and Consumer Services, 21, 249-257. https://doi.org/10.1016/j.jretconser.2014.01.004

[35] Widodo, E., Takahashi, K., Morikawa, K., Pujawan, N. and Santosa, B. (2009) Managing Sales Return in Dual Sales Channel: An Analysis If Its Product Substitution. International Journal of Industrial and Systems Engineering, 10, 823-835.

[36] Widodo, E., Takahashi, K., Morikawa, K., Pujawan, N. and Santosa, B. (2010) Managing Sales Return in Dual Sales Channel: Common Return versus Cross-Channel Return Analysis. International Multi-Conference of Engineers and Computer Scientists, Hong Kong.

[37] Radhi, M. and Zhang, G. (2018) Pricing Policies for a Dual-Channel Retailer with Cross-Channel Returns. Computers \& Industrial Engineering, 119, 63-75. https://doi.org/10.1016/j.cie.2018.03.020

[38] Radhi M. and Zhang G. (2019) Optimal Cross-Channel Return Policy in Dual-Channel Retailing Systems. International Journal of Production Economics, 210, 184-198. https://doi.org/10.1016/j.ijpe.2019.01.014

[39] Cai, G., Zhang Z.G. and Zhang, M. (2009) Game Theoretical Perspectives on Dual-Channel Supply Chain Competition with Price Discount and Pricing Schemes. International Journal of Production Economics, 117, 80-96. https://doi.org/10.1016/j.ijpe.2008.08.053

[40] Chen, J., Zhang, H. and Sun, Y. (2012) Implementing Coordination Contracts in a Manufacturer Stackelberg Dual-Channel Supply Chain. Omega, 40, 571-583. https://doi.org/10.1016/j.omega.2011.11.005

[41] Geng, Q. and Mallik, S. (2007) Inventory Competition and Allocation in a Multi Channel Distribution System. European Journal of Operational Research, 182, 704-729. https://doi.org/10.1016/j.ejor.2006.08.041

[42] Ingene, C. and Parry, M. (1995) Channel Coordination When Retailers Compete. Marketing Science, 14, 360-377. https://doi.org/10.1287/mksc.14.4.360

[43] Kaya, O. (2011) Outsourcing vs. In-House Production: A Comparison of Supply Chain Contracts with Effort Dependent Demand. Omega, 39, 168-178. https://doi.org/10.1016/j.omega.2010.06.002

[44] Cachon, G.P. and Lariviere, M.A. (2005) Supply Chain Coordination with Revenue Sharing Contracts: Strengths and Limitations. Management Science, 51, 30-44. https://doi.org/10.1287/mnsc.1040.0215

[45] Boyaci, T. (2005) Competitive Stocking and Coordination in a Multiple-Channel Distribution System. IIE Transactions, 37, 407-427. https://doi.org/10.1080/07408170590885594

[46] Zhang, P., Xiong, Y. and Xiong, Z. (2015) Coordination of a Dual-Channel Supply Chain after Demand or Production Cost Disruptions. International Journal of Production Research, 53, 3141-3160. https://doi.org/10.1080/00207543.2014.975853

[47] Xu, J., Qi, Q. and Bai, Q. (2018) Coordinating a Dual-Channel Supply Chain with Price Discount Contracts under Carbon Emission Capacity Regulation. Applied Mathematical Modelling, 56, 449-468. https://doi.org/10.1016/j.apm.2017.12.018

[48] Cai, G. (2010) Channel Selection and Coordination in Dual-Channel Supply Chains. Journal of Retailing, 86, 22-36. https://doi.org/10.1016/j.jretai.2009.11.002

[49] Zhang, Z., Liu, S. and Niu, B. (2020) Coordination Mechanism of Dual-Channel 
Closed-Loop Supply Chains Considering Product Quality and Return. Journal of Cleaner Production, 248, Article ID: 119273.

https://doi.org/10.1016/j.jclepro.2019.119273

[50] Huang, W. and Swaminathan, J.M. (2009) Introduction of a Second Channel: Implications for Pricing and Profits. European Journal of Operational Research, 194, 258-279. https://doi.org/10.1016/j.ejor.2007.11.041

[51] Mukhopadhyay, S.K., Yao, D.Q. and Yue, X.H. (2008) Information Sharing of Value-Adding Retailer in a Mixed Channel Hi-Tech Supply Chain. Journal of Business Research, 61, 950-958. https://doi.org/10.1016/j.jbusres.2006.10.027

[52] Kevin, L.W. (2002) Managing Channels of Distribution in the Age of Electronic Commerce. Industrial Marketing Management, 31, 95-102.

https://doi.org/10.1016/S0019-8501(01)00181-X

[53] Cavallo, A. (2017) Are Online and Offline Prices Similar? Evidence from Large Multi-Channel Retailers. American Economic Review, 107, 283-303. https://doi.org/10.1257/aer.20160542

[54] Anderson, E.T., Hansen, K., Simester, D. and Wang L.K. (2006) How Are Demand and Returns Related? Theory and Empirical Evidence. Working Paper, Kellogg School of Management, Northwestern University, Evanston.

[55] Hess, J. and Mayhew, G. (1997) Modeling Merchandise Returns in Direct Marketing. Journal of Direct Marketing, 11, 20-35.

https://doi.org/10.1002/(SICI)1522-7138(199721)11:2<20::AID-DIR4>3.0.CO;2-\# 


\section{Appendix A. Appendices}

\section{Appendix 1. Proof of Proposition 1}

According to formula (8), we have

$$
\begin{gathered}
\frac{\partial \pi_{r}^{d}}{\partial q_{r}}=\left(1-\beta_{r}\right) p-w-\left(1-\beta_{r}\right) p F\left(\frac{q_{r}+r_{1} p}{\theta}-D\right) \\
\frac{\partial^{2} \pi_{r}^{d}}{\partial q_{r}^{2}}=-\frac{\left(1-\beta_{r}\right) p}{\theta} f\left(\frac{q_{r}+r_{1} p}{\theta}-D\right)<0 \\
\frac{\partial \pi_{r}^{d}}{\partial p}=\left(1-\beta_{r}\right) q_{r}-\left(1-\beta_{r}\right) \theta \int_{-U}^{\frac{q_{r}+r_{1} p}{\theta}-D} F(x) \mathrm{d} x-\left(1-\beta_{r}\right) p r_{1} F\left(\frac{q_{r}+r_{1} p}{\theta}-D\right) \\
\frac{\partial^{2} \pi_{r}^{d}}{\partial p^{2}}=-2\left(1-\beta_{r}\right) r_{1} F\left(\frac{q_{r}+r_{1} p}{\theta}-D\right)-\frac{\left(1-\beta_{r}\right) p r_{1}^{2}}{\theta} f\left(\frac{q_{r}+r_{1} p}{\theta}-D\right)<0 \\
\frac{\partial \pi_{r}^{d}}{\partial p \partial q_{r}}=1-\beta_{r}-\left(1-\beta_{r}\right) F\left(\frac{q_{r}+r_{1} p}{\theta}-D\right)-\frac{\left(1-\beta_{r}\right) r_{1} p}{\theta} f\left(\frac{q_{r}+r_{1} p}{\theta}-D\right)
\end{gathered}
$$

We can know that the risk-neutral traditional retailer's optimal solutions satisfy the following equations:

$$
\left\{\begin{array}{l}
\left(1-\beta_{r}\right) p-w-\left(1-\beta_{r}\right) p F\left(\frac{q_{r}+r_{1} p}{\theta}-D\right)=0 \\
\left(1-\beta_{r}\right) q_{r}-\left(1-\beta_{r}\right) \theta \int_{-U}^{\frac{q_{r}+r_{1} p}{\theta}-D} F(x) \mathrm{d} x-\left(1-\beta_{r}\right) p r_{1} F\left(\frac{q_{r}+r_{1} p}{\theta}-D\right)=0
\end{array}\right.
$$

Then can get:

$$
\begin{gathered}
q_{r}^{d^{*}}=(U+D) \theta-r_{1} p^{d^{*}}-\frac{2 u \theta w}{\left(1-\beta_{r}\right) p_{r}^{d^{*}}}, \\
2 r_{1} p_{r}^{d^{* 3}}-\frac{r_{1} w p_{r}^{d^{*} 2}}{1-\beta_{r}}-D \theta p_{r}^{d^{* 2}}+\frac{\theta U w^{2}}{\left(1-\beta_{r}\right)^{2}}=0 .
\end{gathered}
$$

Note the Hessian matrix $\boldsymbol{H}_{0}$ is as following:

$$
\begin{gathered}
\boldsymbol{H}_{0}=\left[\begin{array}{lr}
-\frac{\left(1-\beta_{r}\right) p}{2 U \theta} & 1-\beta_{r}-\left(1-\beta_{r}\right) F\left(\frac{q_{r}+r_{1} p}{\theta}-D\right)-\frac{\left(1-\beta_{r}\right) r_{1} p}{2 U \theta} \\
1-\beta_{r}-\left(1-\beta_{r}\right) F\left(\frac{q_{r}+r_{1} p}{\theta}-D\right)-\frac{\left(1-\beta_{r}\right) r_{1} p}{2 U \theta} & \left.-2\left(1-\beta_{r}\right) r_{1} F\left(\frac{q_{r}+r_{1} p}{\theta}-D\right)-\frac{\left(1-\beta_{r}\right) p r_{1}^{2}}{2 U \theta}\right] \\
& \left.\left.\right|_{0}\right|_{p=p^{*}, q_{r}=q^{*}}=\left(1-\beta_{r}\right)^{2}\left[\frac{r_{1} p^{d^{*}}}{U \theta}+F\left(x_{0}\right)\left(1-F\left(x_{0}\right)\right)-1+F\left(x_{0}\right)\right] \\
= & \left(1-\beta_{r}\right)^{2}\left[\frac{r_{1} p^{d^{*}}}{U \theta}-1+F\left(x_{0}\right)\left(1-F\left(x_{0}\right)\right)+F\left(x_{0}\right)\right] \\
= & \left(1-\beta_{r}\right)^{2}\left[F\left(x_{0}\right)\left(1-F\left(x_{0}\right)\right)+F\left(x_{0}\right)+\frac{D-U}{\theta}+\frac{r_{1} w(1-\beta) p^{d^{*} 2}-U \theta w^{2}}{U \theta\left(1-\beta_{r}\right)^{2} p^{d^{* 2}}}\right] \\
\text { where, } F\left(x_{0}\right)
\end{array}\right] \\
F\left(\frac{q_{r}^{d^{*}}+r_{1} p^{d^{*}}}{\theta}-D\right) .
\end{gathered}
$$


Because $\quad r_{1} p^{d^{*}}-U \theta=\frac{(D-3 U) \theta}{2}+U \theta F\left(x_{0}\right)\left(1-\frac{F\left(x_{0}\right)}{2}\right)+\frac{r_{1} w}{2\left(1-\beta_{r}\right)}$, when $D>3 U$ is satisfied, then $\left|\boldsymbol{H}_{0}\right|_{p=p^{*}, q_{r}=q_{r}^{d^{*}}}>0$. There exists a unique equilibrium solution $\left(q_{r}^{d^{*}}, p^{d^{*}}\right)$.

According to formula (9), we have

$$
\begin{gathered}
\frac{\partial \pi_{o}^{d}}{\partial q_{o}}=\left(1-\beta_{o}\right) p-w-\left(1-\beta_{o}\right) p F\left(\frac{q_{o}+r_{2} p}{1-\theta}-D\right) \\
\frac{\partial^{2} \pi_{o}^{d}}{\partial q_{o}^{2}}=\frac{\left(1-\beta_{o}\right) p}{1-\theta} f\left(\frac{q_{o}+r_{2} p}{1-\theta}-D\right)<0
\end{gathered}
$$

Then, we can get the risk-neutral online retailer's optimal order quantity is as following the equation:

$$
\left(1-\beta_{o}\right) p-\left(1-\beta_{o}\right) p F\left(\frac{q_{o}+r_{2} p}{1-\theta}-D\right)=0,
$$

that is

$$
q_{0}^{d^{*}}=(U+D)(1-\theta)-r_{2} p^{d^{*}}-\frac{2 u(1-\theta) w}{\left(1-\beta_{o}\right) p^{d^{*}}} .
$$

From this we can get the profit function of suppliers as follows:

$$
\pi_{m}^{d}=w\left(U+D-r_{1} p-r_{2} p-\frac{2 U \theta w}{\left(1-\beta_{r}\right) p}-\frac{2 U(1-\theta) w}{\left(1-\beta_{o}\right) p}\right)
$$

Then, we can get $\pi_{m}^{d}$ is a concave function about $w$, and the supplier's optimal wholesale price satisfies the following equation:

$$
U+D-r_{1} p^{d^{*}}-r_{2} p^{d^{*}}-\frac{4 U \theta w^{d^{*}}}{\left(1-\beta_{r}\right) p^{d^{*}}}-\frac{4 U(1-\theta) w^{d^{*}}}{\left(1-\beta_{o}\right) p^{d^{*}}}=0 .
$$

\section{Appendix 2}

Simplify the formula (14), we can obtain

$$
\begin{aligned}
& \operatorname{CVaR}^{\eta}\left(\pi_{r}^{d}\right) \\
& =\max _{v \in \mathbb{R}}\left\{v+\frac{1}{\eta} E\left[\min \left(\left(\left(1-\beta_{r}\right) p-w\right) q_{r}-\left(1-\beta_{r}\right) p\left(q_{r}-D_{r}\right)^{+}-v, 0\right)\right]\right\}
\end{aligned}
$$

1) If $\left(\left(1-\beta_{r}\right) p-w\right) q_{r}-v \leq 0$, $\left(\left(1-\beta_{r}\right) p-w\right) q_{r}-v-\left(1-\beta_{r}\right) p\left(q_{r}-D_{r}\right)^{+} \leq 0$ must be established, then

$$
\begin{aligned}
& \operatorname{CVaR}^{\eta}\left(\pi_{r}^{d}\right) \\
& =\max _{v \in \mathbb{R}}\left\{v\left(1-\frac{1}{\eta}\right)+\frac{1}{\eta} E\left[\left(\left(1-\beta_{r}\right) p-w\right) q_{r}-\left(1-\beta_{r}\right) p\left(q_{r}-D_{r}\right)^{+}\right]\right\}
\end{aligned}
$$

According to $\frac{\partial \operatorname{CVaR}^{\eta}\left(\pi_{r}^{d}\right)}{\partial v}=1-\frac{1}{\eta}<0$, get the $\operatorname{CVaR}^{\eta}\left(\pi_{r}^{d}\right)$ is a decreasing function of $v$. Because $\left(\left(1-\beta_{r}\right) p-w\right) q_{r}-v \leq 0$, so $v^{*}=\left(\left(1-\beta_{r}\right) p-w\right) q_{r}$. 


$$
\begin{aligned}
\operatorname{CVaR}^{\eta}\left(\pi_{r}^{d}\right) & =v+\frac{1}{\eta} E\left[-\left(1-\beta_{r}\right) p\left(q_{r}-D_{r}\right)^{+}\right] \\
& =v-\frac{\left(1-\beta_{r}\right) p \theta}{\eta} \int_{-U}^{\frac{q_{r}-r_{1} p}{\theta}-D} F x \mathrm{~d} x \\
& =\left(\left(1-\beta_{r}\right) p-w\right) q_{r}-\frac{\left(1-\beta_{r}\right) p \theta}{\eta} \int_{-U}^{\frac{q_{r}-r_{1} p}{\theta}-D} F(x) \mathrm{d} x
\end{aligned}
$$

2) If $\left(\left(1-\beta_{r}\right) p-w\right) q_{r}-v>0$, then

$$
\begin{aligned}
& \operatorname{CVaR}^{\eta}\left(\pi_{r}^{d}\right) \\
& =\max _{v \in \mathbb{R}}\left\{v+\frac{1}{\eta} E\left[\min \left(\left(\left(1-\beta_{r}\right) p-w\right) q_{r}-\left(1-\beta_{r}\right) p\left(q_{r}-D_{r}\right)^{+}-v, 0\right)\right]\right\}
\end{aligned}
$$$$
=\max _{v \in \mathbb{R}}\left\{v+\frac{1}{\eta} \int_{-U}^{\frac{w q_{r}+v}{\left(1-\beta_{r}\right) p \theta}+\frac{r_{1} p}{\theta}-D}\left(\left(\left(1-\beta_{r}\right) p-w\right) q_{r}-\left(1-\beta_{r}\right) p\left(q_{r}-D_{r}\right)^{+}-v\right) f(x) \mathrm{d} x\right\}
$$

Let

$$
G(v)=v+\frac{1}{\eta} \int_{-U}^{\frac{w q_{r}+v}{\left(1-\beta_{r}\right) p \theta}+\frac{r_{1} p}{\theta}-D}\left(\left(\left(1-\beta_{r}\right) p-w\right) q_{r}-\left(1-\beta_{r}\right) p\left(q_{r}-D_{r}\right)^{+}-v\right) \mathrm{d} F(x),
$$

then $\frac{\partial G(v)}{\partial v}=1-\frac{1}{\eta} \int_{-U}^{\frac{w q_{r}+v}{(1-\beta) p \theta}+\frac{r_{1} p}{\theta}-D} \mathrm{~d} F(x)$. From $\frac{\partial G(v)}{\partial v}=0$, we can obtain that $v^{*}=\left(1-\beta_{r}\right) p \theta F^{-1}(\eta)+\left(1-\beta_{r}\right) p \theta D-r_{1} p^{2}\left(1-\beta_{r}\right)-w q_{r}$.

$$
\operatorname{CVaR}^{\eta}\left(\pi_{r}^{d}\right)=\left(1-\beta_{r}\right) p \theta F^{-1}(\eta)+\left(1-\beta_{r}\right) p \theta D-r_{1} p^{2}\left(1-\beta_{r}\right)
$$

Thus,

$$
-w q_{r}-\frac{\left(1-\beta_{r}\right) p \theta}{\eta} \int_{-U}^{F^{-1}(\eta)} F(x) \mathrm{d} x
$$

- Because

$C V a R$ is a continuous risk measure method, we get

$$
\begin{aligned}
& \left(\left(1-\beta_{r}\right) p-w\right) q_{r}-\frac{\left(1-\beta_{r}\right) p \theta}{\eta} \int_{-U}^{\frac{q_{r}-r_{1} p}{\theta}-D} F(x) \mathrm{d} x \\
& =\left(1-\beta_{r}\right) p \theta F^{-1}(\eta)+\left(1-\beta_{r}\right) p \theta D-r_{1} p^{2}\left(1-\beta_{r}\right) \\
& -w q_{r}-\frac{\left(1-\beta_{r}\right) p \theta}{\eta} \int_{-U}^{F^{-1}(\eta)} F(x) \mathrm{d} x \\
& q_{r}-\theta F^{-1}(\eta)-\theta D+r_{1} p-\frac{\theta}{\eta}\left[\int_{-U}^{\frac{q_{r}-r_{1} p}{\theta}-D} F(x) \mathrm{d} x-\int_{-U}^{F^{-1}(\eta)} F(x) \mathrm{d} x\right]=0 .
\end{aligned}
$$

So, we gain $q_{r}=\theta D-r_{1} p+\theta F^{-1}(\eta)$.

Comprehensive to is it can know that $C V a R$ is simplified as fowling:

$$
\operatorname{CVaR}^{\eta}\left(\pi_{r}^{d}\right)=\left\{\begin{array}{c}
\left(1-\beta_{r}\right) p q_{r}-w q_{r}-\frac{\left(1-\beta_{r}\right) p \theta}{\eta} \int_{-U}^{\frac{q_{r}+r_{1} p}{\theta}-D} F(x) \mathrm{d} x \\
\quad \text { if } q_{r} \leq \theta D-R_{1} P+\theta F^{-1}(\eta) \\
\left(1-\beta_{r}\right) p \theta F^{-1}(\eta)+\left(1-\beta_{r}\right) p \theta D-r_{1} p^{2}\left(1-\beta_{r}\right)-w q_{r}-\frac{\left(1-\beta_{r}\right) p \theta}{\eta} \int_{-U}^{F^{-1}(\eta)} F(x) \mathrm{d} x \\
\text { if } q_{r}>\theta D-R_{1} P+\theta F^{-1}(\eta)
\end{array}\right.
$$

\section{Appendix 3. Proof of Proposition 2}

According to formula (16), we have 


$$
\begin{aligned}
& \frac{\partial \operatorname{CVaR}^{\eta}\left(\pi_{r}^{c}\right)}{\partial p}=\left(1-\beta_{r}\right) q_{r}-\frac{\left(1-\beta_{r}\right) \theta}{\eta} \int_{-U}^{\frac{q_{r}+r_{1} p}{\theta}-D} F(x) \mathrm{d} x \\
& -\frac{\left(1-\beta_{r}\right) r_{1} p}{\eta} F\left(\frac{q_{r}+r_{1} p}{\theta}-D\right) \\
& \frac{\partial^{2} \operatorname{CVaR}^{\eta}\left(\pi_{r}^{c}\right)}{\partial p^{2}}=-\frac{2 r_{1}\left(1-\beta_{r}\right)}{\eta} F\left(\frac{q_{r}+r_{1} p}{\theta}-D\right) \\
& -\frac{r_{1}^{2} p\left(1-\beta_{r}\right)}{\theta \eta} f\left(\frac{q_{r}+r_{1} p}{\theta}-D\right) \\
& <0 \\
& \frac{\partial \operatorname{CVaR}^{\eta}\left(\pi_{r}^{c}\right)}{\partial q_{r}}=\left(1-\beta_{r}\right) p-w-\frac{\left(1-\beta_{r}\right) p}{\eta} F\left(\frac{q_{r}+r_{1} p}{\theta}-D\right), \\
& \frac{\partial^{2} \operatorname{CVaR}^{\eta}\left(\pi_{r}^{c}\right)}{\partial q_{r}^{2}}=-\frac{\left(1-\beta_{r}\right) p}{\eta \theta} f\left(\frac{q_{r}+r_{1} p}{\theta}-D\right)<0, \\
& \frac{\partial^{2} \operatorname{CVar}^{\eta}\left(\pi_{r}^{c}\right)}{\partial q_{r} \partial p}=1-\beta_{r}-\frac{1-\beta_{r}}{\eta} F\left(\frac{q_{r}+r_{1} p}{\theta}-D\right)-\frac{r_{1} p\left(1-\beta_{r}\right)}{\eta \theta} f\left(\frac{q_{r}+r_{1} p}{\theta}-D\right)
\end{aligned}
$$

Note the Hessian matrix $\boldsymbol{H}_{1}$ is as following:

$$
\begin{aligned}
& \boldsymbol{H}_{1}=\left[\begin{array}{lr}
-\frac{\left(1-\beta_{r}\right) p}{2 U \eta \theta} & 1-\beta_{r}-\frac{1-\beta_{r}}{\eta} F\left(\frac{q_{r}+r_{1} p}{\theta}-D\right)-\frac{r_{1} p\left(1-\beta_{r}\right)}{2 U \eta \theta} \\
1-\beta_{r}-\frac{1-\beta_{r}}{\eta} F\left(\frac{q_{r}+r_{1} p}{\theta}-D\right)-\frac{r_{1} p\left(1-\beta_{r}\right)}{2 U \eta \theta} & -\frac{2 r_{1}\left(1-\beta_{r}\right)}{\eta} F\left(\frac{q_{r}+r_{1} p}{\theta}-D\right)-\frac{r_{1}^{2} p\left(1-\beta_{r}\right)}{2 U \theta \eta}
\end{array}\right] \\
& \left|\boldsymbol{H}_{1}\right|=\left(1-\beta_{r}\right)^{2}\left[\frac{F\left(\frac{q_{r}+r_{1} p}{\theta}-D\right)}{\eta}\left(2-F\left(\frac{q_{r}+r_{1} p}{\theta}-D\right)\right)+\frac{r_{1} p-U \eta \theta}{U \eta \theta}\right] \text {, } \\
& r_{1} p-U \eta \theta=\frac{D-U(1+2 \eta) \theta}{2}+U \theta F\left(\frac{q_{r}+r_{1} p}{\theta}-D\right) \\
& \times\left(1-\frac{1}{2 \eta} F\left(\frac{q_{r}+r_{1} p}{\theta}-D\right)\right)+\frac{r_{1} w}{2\left(1-\beta_{r}\right)}
\end{aligned}
$$

satisfied, $r_{1} p>U \theta \eta$, so get $\left|\boldsymbol{H}_{1}\right|>0$. Therefore, there exists a unique optimal pricing and order quantity. The risk-averse traditional retailer's optimal solutions satisfy the following equations:

$$
\left\{\begin{array}{l}
\left(1-\beta_{r}\right) q_{r}-\frac{\left(1-\beta_{r}\right) \theta}{\eta} \int_{-U}^{\frac{q_{r}+r_{1} p}{\theta}-D} F(x) \mathrm{d} x-\frac{\left(1-\beta_{r}\right) r_{1} p}{\eta} F\left(\frac{q_{r}+r_{1} p}{\theta}-D\right)=0 \\
\left(1-\beta_{r}\right) p-w-\frac{\left(1-\beta_{r}\right) p}{\eta} F\left(\frac{q_{r}+r_{1} p}{\theta}-D\right)=0
\end{array}\right.
$$

Then can get:

$$
\begin{gathered}
q_{r}^{c^{*}}=(D-U) \theta-r_{1} p^{c^{*}}+\frac{2 U \theta \eta\left(\left(1-\beta_{r}\right) p^{c^{*}}-w\right)}{\left(1-\beta_{r}\right) p^{c^{*}}}, \\
2 r_{1} p^{c^{* 3}}\left(1-\beta_{r}\right)^{2}-r_{1} w p^{c^{* 2}}\left(1-\beta_{r}\right)-(D-(1-\eta) U) \theta p^{c^{* 2}}(1-\beta)^{2}+\theta U \eta w^{2}=0 .
\end{gathered}
$$


According to formula (17), we have

$$
\begin{gathered}
\frac{\partial C \operatorname{Var}\left(\pi_{o}^{c}\right)}{\partial q_{o}}=\left(1-\beta_{o}\right) p-w-\frac{\left(1-\beta_{o}\right) p}{\eta} F\left(\frac{q_{o}+r_{2} p}{1-\theta}-D\right) \\
\frac{\partial^{2} C \operatorname{VaR}\left(\pi_{o}^{c}\right)}{\partial q_{o}^{2}}=\frac{\left(1-\beta_{o}\right) p}{(1-\theta) \eta} f\left(\frac{q_{o}+r_{2} p}{1-\theta}-D\right)<0
\end{gathered}
$$

Then, we can get the risk-averse online retailer's optimal order quantity is as following the equation:

$$
\left(1-\beta_{o}\right) p-w-\frac{\left(1-\beta_{o}\right) p}{\eta} F\left(\frac{q_{o}+r_{2} p}{1-\theta}-D\right)=0,
$$

that is

$$
q_{o}^{c^{*}}=(D-U)(1-\theta)-r_{2} p^{c^{*}}+\frac{2 u \eta(1-\theta)\left(\left(1-\beta_{o}\right) p^{c^{*}}-w\right)}{\left(1-\beta_{o}\right) p^{c^{*}}} .
$$

From this we can get the profit function of suppliers as follows:

$$
\pi_{m}^{c^{*}}=w\left(U+D-r_{1} p-r_{2} p+2 U \eta-\frac{2 U \eta \theta w}{\left(1-\beta_{r}\right) p}-\frac{2 U \eta(1-\theta) w}{\left(1-\beta_{o}\right) p}\right)
$$

Then, we can get $\pi_{m}^{c}$ is a concave function about $w$, and the supplier's optimal wholesale price satisfies the following equation:

$$
U+D-r_{1} p^{c^{*}}-r_{2} p^{c^{*}}+2 U \eta-\frac{4 U \eta \theta w^{c^{*}}}{\left(1-\beta_{r}\right) p^{c^{*}}}-\frac{4 U \eta(1-\theta) w^{c^{*}}}{\left(1-\beta_{o}\right) p^{d^{*}}}=0
$$

\section{Appendix 4. Proof of Proposition 3}

1) Let $x_{1}=\frac{\partial p^{c^{*}}}{\partial \beta_{r}}$, since

$$
2 r_{1} x_{1}-\frac{r_{1} w}{\left(1-\beta_{r}\right)^{2}}+\frac{2 \eta U \eta w^{2}}{\left(1-\beta_{r}\right)^{3} p^{c^{* 3}}}\left(p^{c^{*}}-\left(1-\beta_{r}\right) x_{1}\right)=0 .
$$

Then

$$
x_{1}=\frac{1}{2} \frac{r_{1} w\left(1-\beta_{r}\right) p^{c^{* 3}}-2 \theta U \eta w^{2} p^{c^{*}}}{r_{1}\left(1-\beta_{r}\right)^{3} p^{c^{*} 3}-\theta U \eta w^{2}\left(1-\beta_{r}\right)} .
$$

when the condition $D>5 U$ is satisfied, then $r_{1} p^{c^{*}}-2 \theta U \eta>0$. Because $\left(1-\beta_{r}\right) p^{c^{*}}>w$, it can see that $r_{1} w\left(1-\beta_{r}\right) p^{c * 3}-2 \theta U \eta w^{2} p^{c^{*}}=w p^{c^{*}}\left(r_{1}\left(1-\beta_{r}\right) p^{c^{*} 2}-2 \theta U \eta w\right)>0$. $r_{1}\left(1-\beta_{r}\right)^{3} p^{c^{* 3}}-\theta U \eta w^{2}\left(1-\beta_{r}\right)>0$ is similarly proof. Thus $\frac{\partial p^{c^{*}}}{\partial \beta_{r}}>0$.

2) According to the formula $q_{r}^{c^{*}}=(D-U) \theta-r_{1} p^{c^{*}}+\frac{2 U \theta \eta\left(\left(1-\beta_{r}\right) p^{c^{*}}-w\right)}{\left(1-\beta_{r}\right) p^{c^{*}}}$, we have $\frac{\partial q_{r}^{c^{*}}}{\partial \beta_{r}}=-r_{1} x_{1}-\frac{2 U \eta \theta w}{\left(1-\beta_{r}\right)^{2} p^{c^{*} 2}}\left(p^{c^{*}}-\left(1-\beta_{r}\right) x_{1}\right)$. 
Because $p^{c^{*}}-\left(1-\beta_{r}\right) x_{1}=\frac{r_{1}\left(1-\beta_{r}\right)^{2} p^{c^{* 3}}\left(2 p^{c^{*}}-\left(1-\beta_{r}\right) w\right)}{2 r_{1}\left(1-\beta_{r}\right)^{2} p^{c^{* 3}}-2 U \eta \theta w^{2}}>0$, then can get $\frac{\partial q_{r}^{c^{*}}}{\partial \beta_{r}}<0$.

3) According to the formula (21), we can have

$$
\begin{aligned}
\frac{\partial \pi_{r}^{c^{*}}}{\partial \beta_{r}}= & \left(\left(1-\beta_{r}\right) x_{1}-p^{c^{*}}\right)\left((D-U) \theta-r_{1} p+U \eta \theta-\frac{U \eta \theta w^{2}}{\left(1-\beta_{r}\right)^{2} p^{c^{*} 2}}\right) . \text { Because } \\
& -r_{1} x_{1}\left(\left(1-\beta_{r}\right) p^{c^{*}}-w\right)
\end{aligned}
$$

$\left(1-\beta_{r}\right) x_{1}-p^{c^{*}}<0,(D-U) \theta-r_{1} p+U \eta \theta-\frac{U \eta \theta w^{2}}{\left(1-\beta_{r}\right)^{2} p^{c^{* 2}}}>0$, and $r_{1} x_{1}\left(\left(1-\beta_{r}\right) p^{c^{*}}-w\right)>0$, it can get $\frac{\partial \pi_{r}^{c^{*}}}{\partial \beta_{r}}<0$.

4) According to the formula (20) can get $\frac{\partial q_{o}^{c^{*}}}{\partial \beta_{r}}=x_{1}\left(\frac{2 U \eta(1-\theta) w}{\left(1-\beta_{o}\right) p^{c^{* 2}}}-r_{2}\right)>0$ and $\frac{\partial q_{o}^{c^{*}}}{\partial \beta_{o}}=-\frac{2 U \eta(1-\theta) w}{\left(1-\beta_{o}\right)^{2} p}<0$

5) According to the formula (22) can get $\frac{\partial \pi_{o}^{c^{*}}}{\partial \beta_{o}}=p^{c^{*}}\left(r_{2} p^{c^{*}}-(1-\theta)(D-U+U \eta)\right)+\frac{U \eta(1-\theta) w}{\left(1-\beta_{o}\right)^{2} p^{c^{*}}}$. $r_{2} p^{c^{*}}<(D-U)(1-\theta)+2 U \eta(1-\theta)\left(1-\frac{w}{\left(1-\beta_{o}\right) p^{c^{*}}}\right)$ can be obtained from $q_{o}^{c^{*}}>0$. Then $\frac{\partial \pi_{o}^{c^{*}}}{\partial \beta_{o}}<p^{c^{*}} U \eta(1-\theta)\left(1-\frac{w}{\left(1-\beta_{o}\right) p^{c^{*}}}\left(2-\frac{w}{\left(1-\beta_{o}\right) p^{c^{*}}}\right)\right)$. Because $0<\frac{w}{\left(1-\beta_{o}\right) p^{c^{*}}}<1$, then $1-\frac{w}{\left(1-\beta_{o}\right) p^{c^{*}}}\left(2-\frac{w}{\left(1-\beta_{o}\right) p^{c^{*}}}\right)<0$. So we get $\frac{\partial \pi_{o}^{c^{*}}}{\partial \beta_{o}}<0$.

Therefore, Proposition 3 holds.

\section{Appendix 5. Proof of Proposition 4}

1) Let $x_{2}=\frac{\partial p^{c^{*}}}{\partial \eta}$, since

$$
2 r_{1} x_{2}-U \theta+\frac{U \theta w^{2}}{\left(1-\beta_{r}\right)^{2} p^{c^{* 2}}}-\frac{2 U \theta \eta w^{2}}{\left(1-\beta_{r}\right)^{2} p^{c * 3}} x_{2}=0 .
$$

Then $x_{2}=\frac{U \theta\left(1-\frac{w^{2}}{\left(1-\beta_{r}\right)^{2} p^{c * 2}}\right)}{2\left(r_{1}-\frac{w^{2}}{\left(1-\beta_{r}\right)^{2} p^{c * 2}}\right)}$. 
Because $1-\frac{w^{2}}{\left(1-\beta_{r}\right)^{2} p^{c * 2}}>0$ and $r_{1}-\frac{w^{2}}{\left(1-\beta_{r}\right)^{2} p^{c * 2}}>0$, it is easy to prove that $x_{2}>0$.

2) According to formula (18), we can know that

$$
\frac{\partial q_{r}^{c^{*}}}{\partial \eta}=-r_{1} x_{2}+2 U \theta-\frac{2 U \theta w}{\left(1-\beta_{r}\right) p^{c^{*}}}+\frac{2 U \theta w}{\left(1-\beta_{r}\right)^{2} p^{c^{* 2}}} x_{2} .
$$

Simplify the above formula to get

$$
\begin{aligned}
\frac{\partial q_{r}^{c^{*}}}{\partial \eta}= & \frac{1}{\left(2 r_{1}\left(1-\beta_{r}\right)^{2} p^{c^{* 3}}-2 U \eta \theta w^{2}\right)\left(1-\beta_{r}\right) p^{c^{*}}}\left(2\left(1-\beta_{r}\right)^{2} p^{c^{*}} \theta^{2} U^{2} \eta w\right. \\
& +r_{1}\left(1-\beta_{r}\right) U \theta w^{2} p^{c^{*}}+r_{1}\left(1-\beta_{r}\right)^{2} p^{c^{*} 3}\left(3\left(1-\beta_{r}\right) p^{c^{*}} U \theta-2 w\right) \\
& \left.+2 \theta^{2} U^{2} \eta w^{2}\left(2\left(1-\beta_{r}\right) p^{c^{*}}-1\right)\right)
\end{aligned}
$$

Because $2 r_{1}\left(1-\beta_{r}\right)^{2} p^{c^{*}}-2 U \eta \theta w^{2}>0$ and $3\left(1-\beta_{r}\right) p^{c^{*}} U \theta-2 w>0$, $2\left(1-\beta_{r}\right) p^{c^{*}}-1>0$, then $\frac{\partial q_{r}^{c^{*}}}{\partial \eta}>0$ is proved.

3) By the formula (20) can be obtained

$$
\frac{\partial q_{o}^{c^{*}}}{\partial \eta}=-r_{2} x_{2}+2 U(1-\theta)\left(1-\frac{w}{\left(1-\beta_{o}\right) p^{c^{*}}}+\frac{2 U \eta(1-\theta) w}{\left(1-\beta_{o}\right) p^{c^{*}}} x_{2}\right) .
$$

According to $2 r_{1} x_{2}=U \theta-\frac{U \theta w^{2}}{\left(1-\beta_{r}\right)^{2} p^{c^{* 2}}} x_{2}$ and simplify the above formula to get, is obtained. Because

$$
\begin{aligned}
\frac{\partial q_{o}^{*}}{\partial \eta}= & \frac{w x_{2}}{r_{1}\left(1-\beta_{o}\right)\left(1-\beta_{r}\right)^{2} p^{c^{* 3}}}\left(2 U \eta(1-\theta)\left(1-\beta_{r}\right)^{2} r_{1} p^{c^{*}}-U \eta \theta\left(1-\beta_{o}\right) r_{2}\right) \\
& +\frac{1}{2 r_{1}\left(1-\beta_{o}\right)\left(1-\beta_{r}\right)^{2} p^{c^{*}}}\left(\left(2 U(1-\theta)\left(1-\beta_{r}\right)^{2} r_{1} p^{c^{*}}\left(2\left(1-\beta_{o}\right) p^{c^{*}}-w\right)\right)\right. \\
& \left.+U\left(1-\beta_{o}\right)\left(\left(1-\beta_{r}\right)^{2} p^{c^{* 2}}\left(2(1-\theta) r_{1}-r_{2} \theta\right)+r_{2} \theta w^{2}\right)\right) .
\end{aligned}
$$

when the condition $\frac{r_{1}}{r_{2}}>\frac{\theta}{2(1-\theta)}$ is satisfied, then $\frac{\partial q_{o}^{c^{*}}}{\partial \eta}>0$.

4) Since the formula (21), we can have

$$
\begin{aligned}
& \frac{\partial \pi_{r}^{c^{*}}}{\partial \eta}=x_{2}\left(1-\beta_{r}\right)\left((D-U+U \eta) \theta-2 r_{1} p^{c^{*}}+\frac{r_{1} w}{1-\beta_{r}}-\frac{U \eta \theta w^{2}}{(1-\beta)^{2} p^{c^{* 2}}}\right) \\
& +U \theta\left(\left(1-\beta_{r}\right) p^{c^{*}}+\frac{w^{2}}{\left(1-\beta_{r}\right) p^{c^{*}}}\right) . \\
& \begin{aligned}
\text { Because } & U \theta\left(\left(1-\beta_{r}\right) p^{c^{*}}+\frac{w^{2}}{\left(1-\beta_{r}\right) p^{c^{*}}}\right) \\
= & \frac{U \theta}{\left(1-\beta_{r}\right) p}\left(\left(1-\beta_{r}\right) p^{c^{*}}\left(\left(1-\beta_{r}\right) p^{c^{*}}-2\right)+w^{2}\right)>0
\end{aligned}
\end{aligned}
$$




$$
\begin{gathered}
(D-U+U \eta) \theta-2 r_{1} p^{c^{*}}+\frac{r_{1} w}{1-\beta_{r}}-\frac{U \eta \theta w^{2}}{(1-\beta)^{2} p^{c^{*} 2}}=0 \text {, then } \frac{\partial \pi_{r}^{c^{*}}}{\partial \eta}<0 . \\
\text { 5) } \begin{aligned}
\frac{\partial \pi_{o}^{c^{*}}}{\partial \eta}= & x_{2}\left(1-\beta_{o}\right)\left(s\left(q_{o}^{*}\right)-r_{2} p^{c^{*}}+\frac{r_{2} w}{1-\beta_{o}}\right) \\
& +\frac{U(1-\theta)}{\left(1-\beta_{o}\right) p^{c^{*}}}\left(\left(1-\beta_{o}\right)^{2} p^{c^{*} 2}-2 w+w^{2}\right)
\end{aligned}
\end{gathered}
$$

where $s\left(q_{o}^{*}\right)=(D-U+U \eta)(1-\theta)-r_{2} p^{c^{*}}-\frac{U \eta(-\theta) w^{2}}{\left(1-\beta_{r}\right)^{2} p^{c^{* 2}}}$. So when the condition $\frac{1-\beta_{o}}{r_{2}} s\left(q_{o}^{*}\right)>\left(1-\beta_{o}\right) p p^{c^{*}}-w$ is satisfied, $\frac{\partial \pi_{o}^{c^{*}}}{\partial \eta}>0$.

6) The above studies proved that $q_{r}^{*}$ and $q_{o}^{*}$ are about $\eta$ monotonically increasing. Again according to the formula (23) can be obtained $\frac{\partial \Pi_{s c}^{*}}{\partial \eta}>0$.

Therefore, Proposition 4 holds.

\section{Appendix 6. Proof of Proposition 5}

According to formula (22), we have

$$
\begin{aligned}
& \frac{\partial \Pi_{s c}}{\partial p}=\left(1-\beta_{r}\right) q_{r}-\frac{\left(1-\beta_{r}\right) \theta}{\eta} \int_{-U}^{\frac{q_{r}+r_{1} p}{\theta}-D} F(x) \mathrm{d} x-\frac{r_{1} p\left(1-\beta_{r}\right)}{\eta} F\left(\frac{q_{r}+r_{1} p}{\theta}-D\right) \\
& +\left(1-\beta_{o}\right) q_{o}-\frac{\left(1-\beta_{o}\right)(1-\theta)}{\eta} \int_{-U}^{\frac{q_{o}+r_{2} p}{1-\theta}-D} F(x) \mathrm{d} x \\
& -\frac{r_{2} p\left(1-\beta_{o}\right)}{\eta} F\left(\frac{q_{o}+r_{2} p}{1-\theta}-D\right) \\
& \frac{\partial^{2} \Pi_{s c}}{\partial p^{2}}=-\frac{2 r_{1} p\left(1-\beta_{r}\right)}{\eta} F\left(\frac{q_{r}+r_{1} p}{\theta}-D\right)-\frac{r_{1}^{2} p\left(1-\beta_{r}\right)}{\theta \eta} f\left(\frac{q_{r}+r_{1} p}{\theta}-D\right) \\
& -\frac{2 r_{2} p\left(1-\beta_{o}\right)}{\eta} F\left(\frac{q_{o}+r_{2} p}{1-\theta}-D\right)-\frac{r_{2}^{2} p\left(1-\beta_{o}\right)}{(1-\theta) \eta} f\left(\frac{q_{o}+r_{2} p}{1-\theta}-D\right) \\
& <0 \\
& \frac{\partial \Pi_{s c}}{\partial q_{r}}=\left(1-\beta_{r}\right) p-\frac{\left(1-\beta_{r}\right) p}{\eta} F\left(\frac{q_{r}+r_{1} p}{\theta}-D\right) \\
& \frac{\partial^{2} \Pi_{s c}}{\partial q_{r}^{2}}=-\frac{\left(1-\beta_{r}\right) p}{\eta \theta} f\left(\frac{q_{r}+r_{1} p}{\theta}-D\right)<0 \\
& \frac{\partial \Pi_{s c}}{\partial q_{o}}=\left(1-\beta_{o}\right) p-\frac{\left(1-\beta_{o}\right) p}{\eta} F\left(\frac{q_{o}+r_{1} 2 p}{1-\theta}-D\right) \\
& \frac{\partial^{2} \Pi_{s c}}{\partial q_{o}^{2}}=-\frac{\left(1-\beta_{o}\right) p}{\eta(1-\theta)} f\left(\frac{q_{o}+r_{1} 2 p}{1-\theta}-D\right)<0 \\
& \frac{\partial^{2} \Pi_{s c}}{\partial p \partial q_{r}}=1-\beta_{r}-\frac{1-\beta_{r}}{\eta} F\left(\frac{q_{r}+r_{1} p}{\theta}-D\right)-\frac{r_{1} p\left(1-\beta_{r}\right)}{\eta \theta} f\left(\frac{q_{r}+r_{1} p}{\theta}-D\right) \\
& \frac{\partial^{2} \Pi_{s c}}{\partial p \partial q_{o}}=1-\beta_{o}-\frac{1-\beta_{o}}{\eta} F\left(\frac{q_{o}+r_{2} p}{1-\theta}-D\right)-\frac{r_{2} p\left(1-\beta_{o}\right)}{\eta(1-\theta)} f\left(\frac{q_{o}+r_{2} p}{1-\theta}-D\right)
\end{aligned}
$$




$$
\frac{\partial^{2} \Pi_{s c}}{\partial q_{o} \partial q_{r}}=0
$$

We can know that the risk-averse traditional retailer's optimal solutions satisfy the following equations:

$$
\left\{\begin{array}{l}
\frac{\partial \Pi_{s c}}{\partial p}=0 \\
\frac{\partial \Pi_{s c}}{\partial q_{r}}=0 \\
\frac{\partial \Pi_{s c}}{\partial q_{o}}=0
\end{array}\right.
$$

Then can get $p^{*}=\frac{(D-U+U \eta)\left(\left(1-\beta_{r}\right) \theta+\left(1-\beta_{o}\right)(1-\theta)\right)}{2 r_{1}\left(1-\beta_{r}\right)+2 r_{2}\left(1-\beta_{o}\right)}$,

$q_{r}^{*}=(D-U) \theta-r_{1} p^{*}+2 U \eta \theta, \quad q_{o}^{*}=(D-U)(1-\theta)-r_{2} p^{*}+2 U \eta(1-\theta)$.

Note the Hessian matrix $\boldsymbol{H}_{2}$ is as following:

$$
\boldsymbol{H}_{2}=\left[\begin{array}{lll}
\frac{\partial^{2} \Pi_{s c}}{\partial p^{2}} & \frac{\partial^{2} \Pi_{s c}}{\partial p \partial q_{r}} & \frac{\partial^{2} \Pi_{s c}}{\partial p \partial q_{o}} \\
\frac{\partial^{2} \Pi_{s c}}{\partial p \partial q_{r}} & \frac{\partial^{2} \Pi_{s c}}{\partial q_{r}^{2}} & \frac{\partial^{2} \Pi_{s c}}{\partial q_{r} \partial q_{o}} \\
\frac{\partial^{2} \Pi_{s c}}{\partial p \partial q_{o}} & \frac{\partial^{2} \Pi_{s c}}{\partial q_{r} \partial q_{o}} & \frac{\partial^{2} \Pi_{s c}}{\partial q_{o}^{2}}
\end{array}\right]
$$

On the equilibrium point $\left(p^{*}, q_{r}^{*}, q_{o}^{*}\right)$, we can get

$$
\left|\boldsymbol{H}_{2}\right|_{\left(p=p^{*}, q_{r}=q_{r}^{*}, q_{o}=q_{o}^{*}\right)}=-\frac{\left(1-\beta_{r}\right)\left(1-\beta_{o}\right) p^{3}}{4 \theta(1-\theta) \eta^{2} U^{2}}\left(2 r_{1}\left(1-\beta_{r}\right)+2 r_{2}\left(1-\beta_{o}\right)\right)<0 .
$$

Meanwhile, we can find

$$
\left|\begin{array}{ll}
\frac{\partial^{2} \Pi_{s c}}{\partial p^{2}} & \frac{\partial^{2} \Pi_{s c}}{\partial p \partial q_{r}} \\
\frac{\partial^{2} \Pi_{s c}}{\partial p \partial q_{r}} & \frac{\partial^{2} \Pi_{s c}}{\partial q_{r}^{2}}
\end{array}\right|=\left(1-\beta_{r}\right)^{2}\left(\frac{2 r_{1} p^{*}}{2 U \theta \eta}+\frac{2 r_{2}\left(1-\beta_{o}\right)}{2 U\left(1-\beta_{r}\right) \theta \eta}+\frac{r_{2}^{2} p^{* 2}\left(1-\beta_{o}\right)}{4 U^{2}\left(1-\beta_{r}\right) \theta^{2} \eta^{2}}\right)>0,
$$

$\frac{\partial^{2} \Pi_{s c}}{\partial p^{2}}<0$. In summary, there exists a unique solution to retail prices and dual channel's optimal order quantity $\left(p^{*}, q_{r}^{*}, q_{o}^{*}\right)$.

\section{Appendix 7. Proof of Proposition 6}

1) Let $x_{3}=\frac{\partial p^{*}}{\partial \eta}$, since

$$
x_{3}=\frac{\left(1-\beta_{r}\right) U \theta+\left(1-\beta_{o}\right)(1-\theta) U}{2 r_{1}\left(1-\beta_{r}\right)+2 r_{2}\left(1-\beta_{o}\right)}>0 .
$$

2) According to the formula $q_{r}^{*}=(D-U+2 U \eta) \theta-r_{1} p^{*}$, we have 


$$
\begin{aligned}
\frac{\partial q_{r}^{*}}{\partial \eta}= & \frac{1}{2 r_{1}\left(1-\beta_{r}\right)+2 r_{2}\left(1-\beta_{o}\right)}\left(3 r_{1}\left(1-\beta_{r}\right) U \theta\right. \\
& \left.+4 r_{2}\left(1-\beta_{o}\right) U \theta-r_{1}\left(1-\beta_{o}\right)(1-\theta) U\right)
\end{aligned} \text {. From } 4 r_{2}>r_{1}, \theta>1-\theta, \text { it can be }
$$

obtained $4 r_{2}\left(1-\beta_{o}\right) U \theta-r_{1}\left(1-\beta_{o}\right)(1-\theta) U>0$, then $\frac{\partial q_{r}^{*}}{\partial \eta}>0$.

3) Taking the first-order partial derivative of $q_{o}^{*}$ with regard to $\eta$, we obtain

$$
\begin{aligned}
\frac{\partial q_{o}^{*}}{\partial \eta}= & \frac{1}{2 r_{1}\left(1-\beta_{r}\right)+2 r_{2}\left(1-\beta_{o}\right)}\left(3 r_{2}\left(1-\beta_{o}\right) U(1-\theta)\right. \\
& \left.+4 r_{1}\left(1-\beta_{r}\right) U(1-\theta)-r_{2}\left(1-\beta_{r}\right) U \theta\right)
\end{aligned}
$$

when the coordination $\frac{r_{1}}{r_{2}}>\frac{\theta}{4(1-\theta)}-\frac{3\left(1-\beta_{o}\right)}{4\left(1-\beta_{r}\right)}$ is stratified, thus $\frac{\partial q_{o}^{*}}{\partial \eta}>0$.

4) The partial derivative of $s\left(q_{r}^{*}\right)$ regarding $\eta$ is

$$
\frac{\partial s\left(q_{r}^{*}\right)}{\partial \eta}=\frac{r_{1}\left(1-\beta_{r}\right) U \theta+2 r_{2}\left(1-\beta_{o}\right) U \theta-r_{1}\left(1-\beta_{o}\right)(1-\theta)}{2 r_{1}\left(1-\beta_{r}\right)+2 r_{2}\left(1-\beta_{o}\right)}
$$

It is easy to get $\frac{\partial s\left(q_{r}^{*}\right)}{\partial \eta}>0$. Similarly, it can be proved that $\frac{\partial s\left(q_{o}^{*}\right)}{\partial \eta}>0$. Because $p^{*}>0, s\left(q_{r}^{*}\right)>0$ and $s\left(q_{o}^{*}\right)>0$, then $\left(1-\beta_{r}\right) p^{*} s\left(q_{r}^{*}\right)+\left(1-\beta_{o}\right) p^{*} s\left(q_{o}^{*}\right)$ increase monotonically as the retailer's risk-averse level $\eta$ increase, so that, $\Pi_{s c}^{*}$ increase monotonically as the retailer's risk-averse level $\eta$ increase. This completes proof.

\section{Appendix 8. Proof of Proposition 7}

1) Let $x_{4}=\frac{\partial p^{*}}{\partial \beta_{r}}$, since

$$
x_{4}=\frac{2\left(1-\beta_{o}\right)(D-U+U \eta)\left(r_{1}(1-\theta)-r_{2} \theta\right)}{\left(2 r_{1}\left(1-\beta_{r}\right)+2\left(1-\beta_{o}\right)\right)^{2}}<0 .
$$

$\frac{\partial q_{r}^{*}}{\partial \beta_{r}}=-r_{1} x_{4}>0, \frac{\partial s\left(q_{r}^{*}\right)}{\partial \beta_{r}}=-r_{1} x_{4}>0$. Let $g_{1}(x)=\left(1-\beta_{r}\right) p^{*} s\left(q_{r}^{*}\right)$, thus the partial derivative of $g_{1}(x)$ regarding $\beta_{r}$ is

$$
\frac{\partial g_{1}(x)}{\partial \beta_{r}}=\left(1-\beta_{r}\right) x_{4}\left((D-U+U \eta) \theta-2 r_{1} p^{*}\right)+p^{*}\left(r_{1} p^{*}-(D-U+U \eta) \theta\right) .
$$

It can be seen from the above, $x_{4}<0,(D-U+U \eta) \theta-2 r_{1} p^{*}>0, p^{*}>0$, $r_{1} p^{*}-(D-U+U \eta) \theta<0$, then $\frac{\partial g_{1}(x)}{\partial \beta_{r}}<0$. Let $g_{2}(x)=\left(1-\beta_{o}\right) p^{*} s\left(q_{o}^{*}\right)$, thus the partial derivative of $g_{2}(x)$ regarding $\beta_{r}$ is

$$
\frac{\partial g_{2}(x)}{\partial \beta_{r}}=\left(1-\beta_{o}\right) x_{4}\left((D-U+U \eta)(1-\theta)-2 r_{2} p^{*}\right) \text {. }
$$

Because $(D-U+U \eta)(1-\theta)-2 r_{2} p^{*}<0$, we can get $\frac{\partial g_{2}(x)}{\partial \beta_{r}}<0$. 
$\Pi_{s c}^{*}=g_{1}(x)+g_{2}(x)$, thus $\Pi_{s c}^{*}$ decrease monotonically as increase $\beta_{r}$.

2) Let $x_{5}=\frac{\partial p^{*}}{\partial \beta_{o}}$, since

$$
x_{5}=\frac{2\left(1-\beta_{r}\right)(D-U+U \eta) \theta\left(r_{2}-r_{1}\right)+2\left(1-\beta_{r}\right) U \eta\left(r_{2} \theta-r_{1}(1-\theta)\right)}{2 r_{1}\left(1-\beta_{r}\right)+2\left(1-\beta_{o}\right)^{2}}>0 .
$$

the partial derivative of $q_{o}^{*}$ regarding $\beta_{r}$ is $\frac{\partial q_{o}^{*}}{\beta_{o}}=-r_{2} x_{5}<0$. The partial derivative of $g_{2}(x)$ regarding $\beta_{o}$ is

$$
\begin{aligned}
\frac{\partial g_{2}(x)}{\partial \beta_{o}}= & \left(1-\beta_{o}\right) x_{5}\left((D-U+U \eta)(1-\theta)-2 r_{2} p^{*}\right) \\
& +p^{*}\left(r_{2} p^{*}-(D-U+U \eta)(1-\theta)\right)
\end{aligned}
$$

It easily obtains $\frac{\partial g_{2}(x)}{\partial \beta_{o}}<0$. Smarmily, $\frac{\partial g_{1}(x)}{\partial \beta_{o}}<0$. To sum up, we can see that $\Pi_{s c}^{*}$ decrease monotonically as increase $\beta_{o}$.

\section{Appendix9. Proof of Corollary 1}

We assume that $p^{c^{*}}=p^{*}=p_{*}, \quad q_{r}^{c^{*}}=q^{*}=q_{*}$. Then there is:

$$
F\left(\frac{q_{*}+r_{1} p_{*}}{\theta}-D\right)=\eta-\frac{w \eta}{\left(1-\beta_{r}\right) p_{*}}=\eta
$$

From the above formulas can be obtained, $w=0$. Therefore the above equation is not valid. Thus we can see that $p^{c^{*}} \neq p^{*}, q_{r}^{c^{*}} \neq q_{r}^{*}$. And because $\Pi_{s_{c}}$ is a joint concave function of $p$ and $q_{r}$ and $q_{o}$, so when $p^{d^{*}} \neq p^{*}$ the profit of the supply chain in the decentralized situation will deviate from the optimal profit in the centralized situation.

\section{Appendix 10. Proof of Proposition 8}

From formula (27), we can see that

$$
\begin{gathered}
\frac{\partial \operatorname{CVaR}^{\eta}\left(\pi_{r}^{s}\right)}{\partial p}=\lambda_{1}\left(1-\beta_{r}\right)\left(q_{r}-\frac{\theta}{\eta} \int_{-U}^{\frac{q_{r}+r_{1} p}{\theta}-D} F(x) \mathrm{d} x\right) \\
-\frac{\lambda_{1}\left(1-\beta_{r}\right) r_{1} p}{\eta} F\left(\frac{q_{r}+r_{1} p}{\theta}-D\right)+\frac{r_{1} b_{1}}{\eta} F\left(\frac{q_{r}+r_{1} p}{\theta}-D\right) \\
\frac{\partial^{2} C V a R^{\eta}\left(\pi_{r}^{s}\right)}{\partial p^{2}}=-\frac{2 \lambda_{1}\left(1-\beta_{r}\right) r_{1}}{\eta} F\left(\frac{q_{r}+r_{1} p}{\theta}-D\right) \\
-\frac{r_{1}^{2}}{2 U \theta \eta}\left(\lambda_{1}\left(1-\beta_{r}\right) p-b_{1}\right)<0 \\
\frac{\partial C V a R^{\eta}\left(\pi_{r}^{s}\right)}{\partial q_{r}}=\lambda_{1}\left(1-\beta_{r}\right) p-w-\frac{\lambda_{1}\left(1-\beta_{r}\right) p-b_{1}}{\eta} F\left(\frac{q_{r}+r_{1} p}{\theta}-D\right) \\
\frac{\partial^{2} C V a R^{\eta}\left(\pi_{r}^{s}\right)}{\partial q_{r}^{2}}=-\frac{\lambda_{1}\left(1-\beta_{r}\right) p-b_{1}}{2 U \theta \eta}<0
\end{gathered}
$$




$$
\begin{aligned}
\frac{\partial^{2} C \operatorname{VaR}^{\eta}\left(\pi_{r}^{s}\right)}{\partial q_{r} \partial p}= & \lambda_{1}\left(1-\beta_{r}\right)-\frac{\lambda_{1}\left(1-\beta_{r}\right)}{\eta} F\left(\frac{q_{r}+r_{1} p}{\theta}-D\right) \\
& -\frac{\lambda_{1}\left(1-\beta_{r}\right) r_{1} p}{2 U \theta \eta}+\frac{r_{1} b_{1}}{2 U \theta \eta}
\end{aligned}
$$

We can know that the risk-averse traditional retailer's optimal solutions satisfy the following equations:

$$
\left\{\begin{array}{l}
\lambda_{1}\left(1-\beta_{r}\right)\left(q_{r}-\frac{\theta}{\eta} \int_{-U}^{\frac{q_{r}+r_{1} p}{\theta}-D} F(x) \mathrm{d} x\right)-\frac{\lambda_{1}\left(1-\beta_{r}\right) r_{1} p}{\eta} F\left(\frac{q_{r}+r_{1} p}{\theta}-D\right)+\frac{r_{1} b_{1}}{\eta} F\left(\frac{q_{r}+r_{1} p}{\theta}-D\right)=0 \\
\lambda_{1}\left(1-\beta_{r}\right) p-w-\frac{\lambda_{1}\left(1-\beta_{r}\right) p-b_{1}}{\eta} F\left(\frac{q_{r}+r_{1} p}{\theta}-D\right)=0
\end{array}\right.
$$

Solving the above equations can be obtained:

$$
\begin{gathered}
q_{r}^{s^{*}}=\frac{\left(\lambda_{1}\left(1-\beta_{r}\right) p^{s^{*}}-w\right) 2 U \eta \theta \lambda_{1}}{\left(1-\beta_{r}\right) p^{s^{*}}-b_{1}}+(D-U) \theta-r_{1} s^{s^{*}} \\
(D-U) \theta-2 r_{1} p^{s^{*}}-\frac{\theta \eta U A^{2}}{B^{2}}+\frac{A}{B} 2 U \eta \theta+\frac{r_{1} w}{\lambda_{1}\left(1-\beta_{r}\right)}=0
\end{gathered}
$$

where, $A=\lambda_{1}\left(1-\beta_{r}\right) p^{s^{*}}-w, B=\lambda_{1}\left(1-\beta_{r}\right) p^{s^{*}}-b_{1}$.

Note the Hessian matrix $\boldsymbol{H}_{3}$ is as following:

$$
\begin{aligned}
& \boldsymbol{H}_{3}=\left[\begin{array}{ll}
\frac{\partial^{2} C \operatorname{VaR}^{\eta}\left(\pi_{r}^{s}\right)}{\partial q_{r}^{2}} & \frac{\partial^{2} C \operatorname{VaR}^{\eta}\left(\pi_{r}^{s}\right)}{\partial q_{r} \partial p} \\
\frac{\partial^{2} C \operatorname{VaR}^{\eta}\left(\pi_{r}^{s}\right)}{\partial p^{2}} & \frac{\partial^{2} C \operatorname{VaR}^{\eta}\left(\pi_{r}^{s}\right)}{\partial p \partial q_{r}}
\end{array}\right] \\
& \left|\boldsymbol{H}_{3}\right|_{p=p^{s^{*}}, q_{r}=q_{r}^{s^{*}}}=-\left(\lambda_{1}\left(1-\beta_{r}\right)\right)^{2}\left(1-\frac{F\left(\frac{q_{r}^{s^{*}}+r_{1} p^{s^{*}}}{\theta}-D\right)}{\eta}\right)^{2} \\
& +\frac{2 \lambda_{1}\left(1-\beta_{r}\right) r_{1}\left(\lambda_{1}\left(1-\beta_{r}\right) p^{s^{*}}-b_{1}\right)}{2 U \theta \eta} \\
& =\frac{F\left(\frac{q_{r}^{s^{*}}+r_{1} p^{s^{*}}}{\theta}-D\right)}{\eta}\left(2-\frac{F\left(\frac{q_{r}^{s^{*}}+r_{1} p^{s^{*}}}{\theta}-D\right)}{\eta}\right) \\
& +\frac{2 \lambda_{1}\left(1-\beta_{r}\right) r_{1}\left(\lambda_{1}\left(1-\beta_{r}\right) p-b_{1}\right)}{2 U \theta \eta}-1 \\
& r_{1} p^{s^{*}}-U \theta \eta=\frac{\theta}{\eta+F\left(x_{0}\right)}\left(D \eta-U\left(2 F^{2}\left(x_{0}\right)-\eta F\left(x_{0}\right)+\eta^{2}+\eta\right)\right) \\
& +\frac{r_{i} b_{1} F\left(x_{0}\right)}{\lambda_{1}\left(1-\beta_{1}\right)\left(\eta+F\left(x_{0}\right)\right)} \text {. }
\end{aligned}
$$


where $F\left(x_{0}\right)=F\left(\frac{q_{r}^{s^{*}}+r_{1} p^{s^{*}}}{\theta}-D\right)$.

According to $\eta^{2}+\eta \leq 2 F^{2}\left(x_{0}\right)-\eta F\left(x_{0}\right)+\eta^{2}+\eta \leq 2+\eta^{2}$ get $r_{1} p^{s^{*}}-U \theta \eta \geq \frac{\theta}{\eta+F\left(x_{0}\right)}\left(\eta-\left(2+\eta^{2}\right) U\right)+\frac{r_{1} b_{1} F\left(x_{0}\right)}{\lambda_{1}\left(1+\beta_{r}\right)\left(\eta+F\left(x_{0}\right)\right)}$. So when the condition $D>\frac{r_{i} b_{1}}{\lambda_{1}\left(1+\beta_{r}\right) \theta}+\frac{\left(2+\eta^{2}\right) U}{\eta}$ is satisfied, $r_{1} p^{s^{*}}-U \theta \eta \geq \frac{r_{1} b_{1}}{\lambda_{1}\left(1-\beta_{r}\right)}$ can be obtained, that is $\frac{2 \lambda_{1}\left(1-\beta_{r}\right) r_{1}\left(\lambda_{1}\left(1-\beta_{r}\right) p-b_{1}\right)}{2 U \theta \eta}-1 \geq 0$. And because $2-\frac{F\left(\frac{q_{r}^{s^{*}}+r_{1} p^{s^{*}}}{\theta}-D\right)}{\eta}>0$, so we can obtain $\left|\boldsymbol{H}_{3}\right|>0$.

From formula (25), we can see that

$$
\begin{gathered}
\frac{\partial \operatorname{CVaR}^{\eta}\left(\pi_{o}^{s}\right)}{\partial q_{o}}=\lambda_{2}\left(1-\beta_{o}\right) p-w-\frac{\lambda_{2}\left(1-\beta_{o}\right) p-b_{2}}{\eta} F\left(\frac{q_{o}+r_{2} p}{1-\theta}-D\right) \\
\frac{\partial^{2} C V^{\prime} R^{\eta}\left(\pi_{o}^{s}\right)}{\partial q_{o}^{2}}=-\frac{\lambda_{2}\left(1-\beta_{o}\right) p-b_{2}}{2 U(1-\theta) \eta}<0
\end{gathered}
$$

From the above formula, it can be see that

$$
q_{o}^{s^{*}}=\frac{\left(\lambda_{2}\left(1-\beta_{o}\right) p^{s^{*}}-w\right) 2 U \eta(1-\theta)}{\lambda_{2}\left(1-\beta_{o}\right) p^{s^{*}}-b_{2}}+(D-U)(1-\theta)-r_{2} p^{s^{*}} .
$$

From this we can get the profit function of suppliers as follows:

$$
\begin{aligned}
\pi_{m}^{s}= & w\left(D-U-r_{1} p-r_{2} p+\frac{2 U \eta \theta\left(\lambda_{1}\left(1-\beta_{r}\right) p-w\right)}{\lambda_{1}\left(1-\beta_{r}\right) p-b_{1}}\right. \\
& \left.-\frac{2 U \eta(1-\theta)\left(\lambda_{2}\left(1-\beta_{o}\right) p-w\right)}{\lambda_{2}\left(1-\beta_{o}\right) p-b_{2}}\right)
\end{aligned}
$$

Then, we can get $\pi_{m}^{s}$ is a concave function about $w$, and the supplier's optimal wholesale price satisfies the following equation:

$$
\begin{aligned}
& D-U-r_{1} p^{s^{*}}-r_{2} p^{s^{*}}+\frac{2 U \eta \theta \lambda_{1}\left(1-\beta_{r}\right) p^{s^{*}}}{\lambda_{1}\left(1-\beta_{r}\right) p^{s^{*}}-b_{1}}-\frac{4 U \eta \theta w^{s^{*}}}{\left(1-\beta_{r}\right) p^{s^{*}} b_{1}} \\
& -\frac{4 U \eta(1-\theta) w^{s^{*}}}{\left(1-\beta_{o}\right) p^{s^{*}}-b_{2}}+\frac{2 U \eta(1-\theta) \lambda_{2}\left(1-\beta_{o}\right) p^{s^{*}}}{\lambda_{2}\left(1-\beta_{o}\right) p^{s^{*}}-b_{2}}=0
\end{aligned}
$$

Summarizing the above formulations, we can get Proposition 8. 